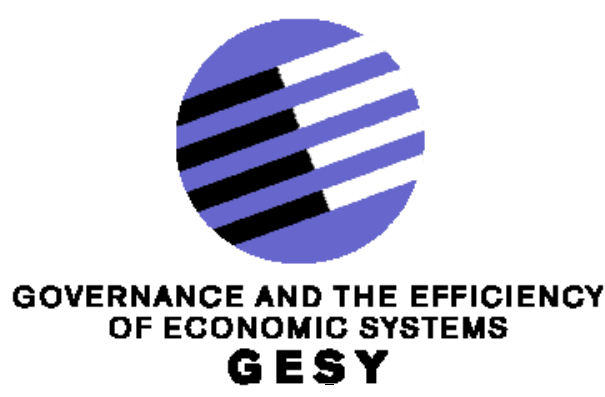

\begin{tabular}{|c|}
\hline Discussion Paper No. 425 \\
Relative Performance Pay \\
in the Shadow of Crisis \\
Matthias Kräkel * \\
Petra Nieken ** \\
\end{tabular}

* University of Bonn

** University of Bonn

Financial support from the Deutsche Forschungsgemeinschaft through SFB/TR 15 is gratefully acknowledged. 


\title{
Relative Performance Pay in the Shadow of Crisis*
}

\author{
Matthias Kräkel $^{\dagger} \quad$ Petra Nieken ${ }^{\ddagger}$
}

\begin{abstract}
We analyze whether incentives from relative performance pay are reduced or enhanced if a department is possibly terminated due to a crisis. Our benchmark model shows that incentives decrease in a severe crisis, but are boosted given a minor crisis since efforts are strategic complements in the former case but strategic substitutes in the latter one. We tested our predictions in a laboratory experiment. The results confirm the effort ranking but show that in a severe crisis individuals deviate from equilibrium significantly stronger than in other situations. This behavior contradicts the benchmark model and leads to a five times higher survival probability of the department. We develop a new theoretical approach that may explain players' behavior.
\end{abstract}

Keywords: crisis; incentives; strategic complements; strategic substitutes; tournament

JEL Classification: C9; J3; J6; M5

\footnotetext{
${ }^{*}$ We would like to thank the participants of the research seminar at the European Business School (Wiesbaden), the brown bag seminar on personnel economics at the University of Cologne, the MAXLab Academic Frontiers Workshop in Magdeburg, the Personnel Economics Meeting in Zurich, the conference on Tournaments, Contests and Relative Performance Evaluation in Raleigh, the Symposium of the German Economic Association of Business Administration in Zurich, the Annual Conference of the Collaborative Research Center "Governance and the Efficiency of Economic Systems" in Tutzing, and in particular Benjamin Bental, Dominique Demougin, Guido Friebel, Oliver Gürtler, Bernd Irlenbusch, Jenny Kragl, Daniel Müller, Patrick Schmitz, Dirk Sliwka, and Michael Waldman for helpful comments. Financial support by the Deutsche Forschungsgemeinschaft (DFG), grant SFB/TR 15, is gratefully acknowledged.

${ }^{\dagger}$ University of Bonn, Department of Economics, Adenauerallee 24-42, D-53113 Bonn, Germany, tel: +49 228 733914, fax: +49 228 739210, e-mail: m.kraekel@uni-bonn.de.

${ }^{\ddagger}$ University of Bonn, Department of Economics, Adenauerallee 24-42, D-53113 Bonn, Germany, tel: +49 228 739213, fax: +49 228 739210, e-mail: petra.nieken@uni-bonn.de.
} 
"Crisis can bring out the best in a company and its people. Rather than yield to pessimism, our organization has moved forward with a renewed sense of purpose to succeed. Through hard work and tough choices, we made significant progress during the past 365 days." (Sergio Marchionne, CEO Chrysler Group LLC, The Wall Street Journal, 2010)

\section{Introduction}

During the recent economic crisis in the U.S. and Europe, companies had to deal with a reduction of demand for their products and reduced profits. Even though the local governments induced "recovery packages" including for instance the option for short-time working, companies often decided to shut down parts of their facilities or to generally downsize their workforce (for more details check Glassner and Galgoczi, 2009). For example, Foot Locker closed 208 of its U.S. stores in 2008 to increase overall efficiency and profits. In the same year, the coffee retailer Starbucks proclaimed to shut down 600 of its underperforming shops in the U.S.. In January 2010, the large European drugstore chain Schlecker announced to eliminate 500 locations, while GAP decided to close 189 retail stores in the U.S. in 2011. These and other cases show that, for technological reasons, companies prefer closing an entire organizational unit or a department to dismissing a certain number of workers at different units. As Bewley (1999) documents, companies with a single location also prefer dissolving whole departments. ${ }^{1}$

Generally, if a company is facing a crisis, workers may lose their jobs or will have to accept substantial wage cuts. The job insecurity perceptions during such a downsizing process lead to a reduction of performance and increased stress (Sverke et al., 2002) a phenomenon which can also be observed in the advance notice period of plant closures (Hansson and Wigblad, 2006). ${ }^{2}$ This strand of literature deals with large companies that were facing a severe crisis and in the end did not manage a turnaround and were forced to downsize or close parts of their businesses. However, little is known about the effects of a looming crisis when there is still a chance to avoid layoffs and closures. Our paper fills this gap in literature as we study the impact of different degrees of crisis on worker motivation. Will the workers reduce effort as the literature on downsizing and plant closures indicates? Or will the workers stick together and try to save their jobs as the quote at the beginning of the paper suggests? Indeed, we can often observe that workers accept wage cuts or offer to work for free for a limited time period in order to save their department (e.g. General Motors, Delta Air Lines).

First, we develop a theoretical model and then test its predictions in a controlled lab experiment. We rely on experimental data instead of company data as it would be very difficult to measure the perceived extent of a crisis and the individual effort reaction of workers using company data. The experiment allows us to induce different likelihoods of termination resulting from a crisis keeping all else equal. In our theoretical model we compare three different cases. We start with the baseline case where a department does not face a crisis and the workers

\footnotetext{
${ }^{1}$ Bewley (1999), chapter 13, analyzes layoffs of 235 companies during recession and finds that "many firms laid off whole departments or large portions of them" (p. 238).

${ }^{2}$ After the closedown decision is made public and the plant is shut down no matter how well it performs, the so called close-down effect leading to enhanced productivity can be observerd.
} 
are motivated by relative performance pay. ${ }^{3}$ The use of relative performance pay in the form of bonus pools, sales contests or rewards is very common in companies to induce incentives. ${ }^{4}$ Moreover, nearly every company uses relative performance evaluation to fill vacant positions via job-promotion contests. In addition, many companies apply forced-ranking systems to avoid leniency and centrality biases when evaluating their employees. As Boyle (2001) reports, about 25 percent of the Fortune 500 companies employ a forced-ranking system (e.g., General Electric, Intel, Cisco Systems, Sun Microsystems). Following the seminal papers by Lazear and Rosen (1981), Green and Stokey (1983), Nalebuff and Stiglitz (1983), O'Keeffe et al. (1984), Malcomson (1984), and Rosen (1986), we model workers' relative performance pay as a rankorder tournament. ${ }^{5}$ We consider a stylized situation of a department with two workers. These two workers compete for relative performance pay, consisting of a non-negative tournament loser prize and a strictly larger winner prize.

In the second and third case we add the possibility of termination due to a crisis. In both cases termination can be avoided if the performance of the department exceeds a certain threshold. Hence, the likelihood of termination is not exogenous but does depend on the workers' efforts. If the threshold is not met, the department will be terminated and the workers will lose the prizes. The second case (minor crisis) corresponds to a situation where the department can avoid termination relatively easily by improving its productivity. Only one worker needs to be successful so that the department meets the survival threshold. Our results show that in this setting efforts are strategic substitutes in the sense of Bulow et al. (1985) meaning that a higher effort of one worker decreases the effort of his opponent. Since each worker wants to make use of this strategic effect, in equilibrium both end up in a situation with higher effort levels compared to the baseline case without crisis.

The third case (severe crisis) corresponds to a situation where termination is very likely and can only be avoided if both workers are successful so that the survival threshold is met. This situation reminds of a team problem as the workers have to stick together in order to avoid termination. The important difference to the existing team literature (see, e.g., van Dijk et al., 2001, or Vandegrift and Yavas, 2011) is that the workers still participate in a tournament and therefore only one of them will be able to collect the winner prize. We show that in this setting efforts are strategic complements in the sense of Bulow et al. (1985) as less effort by one of the workers induces less effort by the other. Hence, we find that the severity of the looming crisis is crucial for its impact on worker motivation. If efforts are strategic substitutes as in the case of a minor crisis, workers will respond with higher effort levels than in the baseline case. If efforts are strategic complements as in the severe crisis, workers will refrain from exerting much effort compared to the baseline case. Thus, our model shows that both observations from above, namely reduced productivity before plant closure announcements as well as enhanced productivity, can be explained based on the plant's (or department's) likelihood

\footnotetext{
${ }^{3}$ Note that if an isolated worker was motivated by an individualized incentive scheme (e.g., bonus pay or piece rates), the interesting interplay of different individuals would be missing. For example, under a quota system, where a worker only receives a certain bonus if his output exceeds this quota, nothing but the quota would change if introducing a crisis.

${ }^{4}$ For example, monetary incentives can be combined with relative performance evaluation (e.g., "employee of the month"), as practiced by Foot Locker.

${ }^{5}$ More recent work comprises Santos Pinto (2010), Cason et al. (2012) and Altmann et al. (2012).
} 
of being terminated.

In our experiment, we test the theoretical predictions. We start with a winner-take-all situation where only the tournament winner receives a positive prize. In a second step we introduce a positive loser prize as a robustness check. Our experimental findings are qualitatively in line with Nash equilibrium behavior: on average, individuals chose highest effort given a minor crisis, but they chose higher effort in the baseline tournament without crisis than in the tournament given a severe crisis. However, in either situation - minor, negligible, and severe crisis - individuals invested significantly more effort than theoretically predicted. While this observation is not unusual for experiments on tournaments (see, e.g., Orrison et al., 2004; Vandegrift et al., 2007; Sheremeta and Zhang, 2010; or Harbring and Irlenbusch 2011), excessive effort supply in a severe crisis compared to situations with a minor or negligible crisis remains a puzzle. In that situation, average effort is more than twice as high compared to the equilibrium effort level. The double amount of effort has a strong implication for the department's survival probability, making it five times higher than in equilibrium.

We discuss possible explanations for this finding based on results of previous experimental studies. As our setting shows similarities to team work or public good experiments, the oversupply may be due to other-regarding preferences. As a further candidate for explaining our empirical puzzle we consider loss aversion, both with exogenous and endogenous reference points. Empirically, however, loss aversion turns out to have no significant influence. Theoretically, we can show that loss aversion cannot explain players' behavior since efforts are again strategic substitutes in a minor crisis but strategic complements in a severe crisis scenario. We therefore develop an alternative approach that takes into account that workers first have to collectively achieve the survival of their department before receiving their personal incomes. This approach meets the observations in the experiment with a zero loser prize as well as the observations on players' behavior under a positive loser prize.

\section{$2 \quad$ Related Literature}

Termination of a department due to poor performance given a crisis is similar to a shutdown of a company following bankruptcy. Both cases typically lead to a collective dismissal of workers. Thus, our paper is related to the literature on the threat of bankruptcy and incentives. Grossman and Hart (1982) and Hart (1995) point out that issuing debt and, thereby, generating a positive probability of bankruptcy can be a powerful instrument to discipline managers. Since bankruptcy is accompanied by the loss of their jobs, managers have strong incentives to exert high effort and make profitable investments. Schmidt (1997) analyzes the disciplining of managers via firm liquidation without explicitly addressing the role of debt. He shows that increased market competition reduces a firm's profits but improves managerial incentives as the likelihood of firm liquidation goes up. Dewatripont and Tirole (1994) as well as Berkovitch and Israel (1996) discuss the combination of CEO compensation and a firm's capital structure as a disciplining device. They particularly address the optimal allocation of control rights within an incomplete-contracting framework. However, none of the papers considers relative performance pay of workers. 
Some papers combine financial and personnel economic issues by analyzing optimal incentives for managers who are primarily responsible for the personnel policy of the firm. Garvey and Swan (1992a) analyze the capital structure of a firm with several hierarchical levels. Moderate debt and the corresponding risk of bankruptcy discipline the firm's CEO to choose optimal bonuses for the divisional managers. In their companion paper, Garvey and Swan (1992b) apply their incentive scheme to a CEO who has to design tournament incentives for workers. Given unverifiable worker performance, tournaments prevent opportunistic behavior by the firm's owner who credibly commits himself to pay the promised tournament prizes. However, tournaments may foster sabotage and eliminate efficient cooperation (e.g., mutual help). To get rid of this problem, Garvey and Swan suggest to discipline the CEO - who dislikes pay inequality - by issuing debt, leading to a positive probability of the firm going bankrupt and the CEO losing his job. In the paper by Gaston (1997), the CEO has full discretion of paying efficiency wages to the firm's workers. Disciplining by debt and the risk of bankruptcy makes the CEO choose a compensation policy that is optimal from the viewpoint of the shareholders. The three papers address the disciplining role of debt for top managers but do not investigate the incentive effects for workers.

Part of the literature on personnel economics discusses the possibility of firm liquidation and its incentive implications for workers instead of managers. Three papers are based on tournament models. Berkowitz and Kotowitz (1993) consider professional partnerships where associates are compensated by relative piece rates or compete in tournaments either for monetary prizes or for promotion to become partners. Since partners are financially constrained, which implies the possibility of the partnership's bankruptcy, the optimal incentive scheme is a promotion-to-partner tournament in order to let the tournament winner participate in the residual claim and, hence, to reduce the risk of bankruptcy. Zabojník and Bernhardt (2001) discuss job-promotion tournaments in heterogeneous firms that differ in productivity and belong to the same competitive market. Tournament prizes are endogenously determined by competition for workers in the labor market. Workers' acquired human capital is not observable by other employers, but promotion to a better job serves as a signal. Introducing an exogenous probability of firm bankruptcy into this setting leads to a positive correlation between a firm's size and productivity, on the one hand, and workers' labor market experience, on the other. Friebel and Matros (2005) also address the possibility of firm bankruptcy in a setting where workers compete in job-promotion tournaments. Since the risk of firm bankruptcy is assumed to be completely exogenous, a higher risk of bankruptcy solely implies a lower expected prize from winning the tournament, which unambiguously reduces incentives. In addition, Friebel and Matros show that promoted workers in firms with higher bankruptcy risk earn higher wages. This result is due to the assumption of competitive markets which force more risky firms to pay higher wages on higher levels in order to be attractive for workers. In contrast to Friebel and Matros, we let the probability of collective dismissal be endogenously determined by workers' effort choices, leading to different scenarios in which efforts are either strategic substitutes or strategic complements. In the Friebel-Matros setting, such different scenarios cannot arise since the exogenous bankruptcy probability does not change the structure of the game.

Our paper is also related to Bernhardt and Mongrain (2010). They consider a kind of 
layoff tournament. First, workers invest in general and firm-specific human capital. Thereafter, the economic situation realizes and nature decides on the fraction of a firm's workforce that has to be laid off. Bernhardt and Mongrain show that a rat race arises and workers overinvest in human capital. This overinvestment serves as an insurance device against dismissal, since firms favor workers with higher human capital when deciding about which workers to retain. Different to our paper, the layoff probability is exogenously given in Bernhardt and Mongrain (2010). In contrast to the papers mentioned in this section, we analyze the incentive effects of a crisis both theoretically and experimentally and show that social preferences may explain our findings.

\section{The Benchmark Model}

We consider relative performance pay of two workers, 1 and 2, who belong to the same department of a company. For example, we can think of a sales contest or a forced-ranking system, which are frequently used in practice. ${ }^{6}$ Based on the outcome of this tournament, the two workers receive monetary incomes $w_{L} \geq 0$ and $w_{H}>w_{L}$. The distribution of these incomes is based on relative performance evaluation. If worker $i$ produces higher output than worker $j(i, j=1,2 ; i \neq j)$ he will receive income $w_{H}$, whereas the other worker $j$ will earn income $w_{L}$. If both workers produce equal output, we apply a fair tie-breaking rule to determine the tournament winner so that each one has the same probability to receive the high income $w_{H}$.

The workers use a stochastic production technology. With probability $p\left(a_{i}\right) \in[0,1]$ worker $i$ realizes high output $\pi_{i}=\bar{\pi}$ in monetary terms, and with probability $1-p\left(a_{i}\right)$ the worker only realizes $\pi_{i}=\underline{\pi}$ with $\underline{\pi} \in(0, \bar{\pi})$. Here, $a_{i} \geq 0$ denotes worker $i$ 's activity or effort level. We assume that $p\left(a_{i}\right)$ is monotonically increasing and concave, being strictly smaller than one in equilibrium, and $p(0)=0$. Exerting higher effort thus increases the probability of a high output $\bar{\pi}$. In other words, concerning two effort levels $a^{\prime}$ and $a^{\prime \prime}$ with $a^{\prime \prime}>a^{\prime}$, the probability distribution $\left(\bar{\pi}, p\left(a^{\prime \prime}\right) ; \underline{\pi}, 1-p\left(a^{\prime \prime}\right)\right)$ dominates the distribution $\left(\bar{\pi}, p\left(a^{\prime}\right) ; \underline{\pi}, 1-p\left(a^{\prime}\right)\right)$ within the meaning of first-order stochastic dominance. The company can only observe realized outputs but not chosen effort levels. Hence, the company has a typical moral-hazard problem. ${ }^{7}$

Effort entails costs to a worker, which are described by the function $c\left(a_{i}\right)$. We assume that $c^{\prime}\left(a_{i}\right)>0, c^{\prime \prime}\left(a_{i}\right)>0, \forall a_{i}>0$, and $c(0)=c^{\prime}(0)=0$. In order to guarantee that workers' equilibrium efforts always increase in the high income $w_{H}$, we impose the technical restriction

$$
\frac{d}{d a_{i}}\left(\frac{c^{\prime}\left(a_{i}\right)}{p^{\prime}\left(a_{i}\right) p\left(a_{i}\right)}\right)>0, \forall a_{i}>0
$$

which is satisfied for $c\left(a_{i}\right)=\frac{c}{3} a_{i}^{3}(c>0)$ and $p\left(a_{i}\right)=a_{i} \in[0,1]$, for example.

Contrary to the standard tournament literature, we consider a scenario in which the workers' department faces a crisis and is possibly terminated in case of poor performance. As a

\footnotetext{
${ }^{6}$ Note that we used a neutral language in the experiment which allows for all of these applications.

${ }^{7}$ The moral-hazard literature has two different strands (see, e.g., Hart and Holmstrom 1987). One strand assumes an explicit production technology $\pi(a, \theta)$ (e.g., $\pi=a+\theta)$ with $\theta$ representing exogenous stochastic influence (state-space formulation). The other strand abstains from an explicit production technology and directly formulates a stochastic relationship between output and effort choice (reduced-form representation). Our setting belongs to the second class of models.
} 
consequence, each worker would be dismissed and earn zero income instead of $w_{L}$ and $w_{H}$. The termination decision may be due to the fact that the department is considered unprofitable by the company. We can also imagine that the termination of critical departments is part of the optimal company policy to punish poor performance. In the following, we assume that both workers will earn incomes $w_{L}$ and $w_{H}$ only if $\pi_{1}+\pi_{2} \geq \Pi$ with $\Pi>0$ as the minimum department profit necessary to cope with the crisis and prevent termination. In case of $\pi_{1}+\pi_{2}<\Pi$, the department cannot cope with the crisis and is dissolved so that the two workers have zero incomes.

We differentiate between three cases: (1) The department's crisis is negligible. This baseline scenario is comparable to a standard tournament without possible termination. Technically, it is characterized by $\Pi \in[0,2 \underline{\pi}]$, i.e., the threshold for the department's profit is so low that termination will never occur. (2) The department faces a minor crisis so that its survival and, hence, workers' incomes are guaranteed if at least one of the workers realizes the high output level, i.e., $\Pi \in(2 \underline{\pi}, \underline{\pi}+\bar{\pi}]$. (3) The department experiences a severe crisis and is, thus, terminated if not both workers realize a high output level, i.e., $\Pi \in(\underline{\pi}+\bar{\pi}, 2 \bar{\pi}]$.

The timing of the game is as follows. First, the workers observe all parameters of the game, especially the threshold $\Pi$ and incomes $w_{L}$ and $w_{H}$. Then they simultaneously choose efforts $a_{1}$ and $a_{2}$. Finally, outputs $\pi_{1}$ and $\pi_{2}$ are realized, and the workers obtain either their incomes or - in case of termination - zero.

\section{Solution to the Benchmark Model}

When solving the workers' problem, we have again to differentiate between the three cases for the threshold value $\Pi$. In the baseline setting with a negligible crisis (i.e., $\Pi \in[0,2 \pi]$ ), there are four possible outcomes. If worker $i$ is better (worse) than his co-worker $j$, worker $i$ is declared tournament winner (loser) and earns income $w_{H}\left(w_{L}\right)$. If both produce the same output, the tournament winner will be determined according to a fair tie-breaking rule. In any case, worker $i$ has to bear his effort cost $c\left(a_{i}\right)$. Altogether, worker $i$ maximizes

$$
\begin{aligned}
E U_{i}\left(a_{i}\right)= & w_{H} p\left(a_{i}\right)\left(1-p\left(a_{j}\right)\right)+\frac{w_{H}+w_{L}}{2}\left[p\left(a_{i}\right) p\left(a_{j}\right)+\left(1-p\left(a_{i}\right)\right)\left(1-p\left(a_{j}\right)\right)\right] \\
& +\left(1-p\left(a_{i}\right)\right) p\left(a_{j}\right) w_{L}-c\left(a_{i}\right) \\
= & \frac{w_{H}+w_{L}}{2}+\frac{w_{H}-w_{L}}{2}\left[p\left(a_{i}\right)-p\left(a_{j}\right)\right]-c\left(a_{i}\right) .
\end{aligned}
$$

The first-order condition shows that each worker has a dominant strategy $a_{b a s e}^{*}$ that is implicitly described as follows: ${ }^{8}$

$$
\frac{1}{2}\left(w_{H}-w_{L}\right) p^{\prime}\left(a_{b a s e}^{*}\right)-c^{\prime}\left(a_{b a s e}^{*}\right)=0 \Leftrightarrow \frac{1}{2}\left(w_{H}-w_{L}\right)=h\left(a_{b a s e}^{*}\right)
$$

with $h(a):=c^{\prime}(a) / p^{\prime}(a)$ being monotonically increasing. As is typical for the standard tournament case, equilibrium efforts increase in the prize spread $w_{H}-w_{L}$, that is, they decrease in the loser prize $w_{L}$ as a kind of fall back position, and increase in the winner prize $w_{H}$. Furthermore,

\footnotetext{
${ }^{8}$ In the following, the subscript "base" indicates the baseline setting while "minor" indicates the minor-crisis setting and "severe" stands for the severe crisis.
} 
the steeper a worker's cost function the lower will be his equilibrium effort.

In case of a minor crisis (i.e., $\Pi \in(2 \underline{\pi}, \underline{\pi}+\bar{\pi}])$, worker $i$ 's strictly concave objective function is given by

$$
E U_{i}\left(a_{i}\right)=w_{H} p\left(a_{i}\right)\left(1-p\left(a_{j}\right)\right)+\frac{w_{H}+w_{L}}{2} p\left(a_{i}\right) p\left(a_{j}\right)+w_{L} p\left(a_{j}\right)\left(1-p\left(a_{i}\right)\right)-c\left(a_{i}\right) .
$$

Compared to equation (2), only the event is missing where both workers perform poorly, because in that case the department is terminated. The first-order condition $E U_{i}^{\prime}\left(a_{i}\right)=0$ can be rewritten as

$$
w_{H}-\frac{w_{H}+w_{L}}{2} p\left(a_{j}\right)=h\left(a_{i}\right) .
$$

In analogy, from worker $j$ 's first-order condition we obtain

$$
w_{H}-\frac{w_{H}+w_{L}}{2} p\left(a_{i}\right)=h\left(a_{j}\right) .
$$

The two reaction functions (5) and (6) show that we have a unique and symmetric equilibrium $\left(a_{1}^{*}, a_{2}^{*}\right)=\left(a_{\text {minor }}^{*}, a_{\text {minor }}^{*}\right)$, implicitly described by

$$
w_{H}-\frac{w_{H}+w_{L}}{2} p\left(a_{\text {minor }}^{*}\right)=h\left(a_{\text {minor }}^{*}\right) .
$$

Implicit differentiation of (7) shows that - as in the standard tournament case - again equilibrium efforts decrease in the loser prize $w_{L}$ and increase in the winner prize $w_{H}$ :

$$
\begin{aligned}
\frac{\partial a_{\text {minor }}^{*}}{\partial w_{L}} & =\frac{-\frac{1}{2} p\left(a_{\text {minor }}^{*}\right)}{\frac{w_{H}+w_{L}}{2} p^{\prime}\left(a_{\text {minor }}^{*}\right)+h^{\prime}\left(a_{\text {minor }}^{*}\right)}<0 \\
\frac{\partial a_{\text {minor }}^{*}}{\partial w_{H}} & =\frac{1-\frac{1}{2} p\left(a_{\text {minor }}^{*}\right)}{\frac{w_{H}+w_{L}}{2} p^{\prime}\left(a_{\text {minor }}^{*}\right)+h^{\prime}\left(a_{\text {minor }}^{*}\right)}>0 .
\end{aligned}
$$

Finally, we have to solve for the equilibrium in the case of a severe crisis (i.e., $\Pi \in(\underline{\pi}+$ $\bar{\pi}, 2 \bar{\pi}]$ ). Here, the department will only survive, if both workers produce a high output. Each worker $i$ maximizes the strictly concave function

$$
E U_{i}\left(a_{i}\right)=\frac{w_{H}+w_{L}}{2} p\left(a_{i}\right) p\left(a_{j}\right)-c\left(a_{i}\right) .
$$

The objective function shows that, when entering the state of a severe crisis, the workers' optimization problem technically looks like a team problem. However, when the workers have achieved that the department survives, they still play a tournament game with one worker receiving the high income $w_{H}$ and the other worker the low income $w_{L}$. Now the first-order condition yields

$$
\frac{w_{H}+w_{L}}{2} p\left(a_{j}\right) p^{\prime}\left(a_{i}\right)=c^{\prime}\left(a_{i}\right) .
$$

Analogously, the first-order condition for worker $j$ gives

$$
\frac{w_{H}+w_{L}}{2} p\left(a_{i}\right) p^{\prime}\left(a_{j}\right)=c^{\prime}\left(a_{j}\right)
$$

There is one symmetric equilibrium where each worker exerts zero effort. Intuitively, if one 
worker chooses zero effort, his probability of realizing the high output will be $p(0)=0$. In this situation, the other worker does not have any chance to avoid the termination of the department. The best he can do is to minimize effort costs by choosing zero effort as well.

Using again the definition $h(a):=c^{\prime}(a) / p^{\prime}(a)$ when combining (9) and (10) leads to

$$
\frac{w_{H}+w_{L}}{2}=\frac{h\left(a_{i}\right)}{p\left(a_{j}\right)}=\frac{h\left(a_{j}\right)}{p\left(a_{i}\right)} \Leftrightarrow h\left(a_{i}\right) p\left(a_{i}\right)=h\left(a_{j}\right) p\left(a_{j}\right) .
$$

Since both sides of the last equation describe the same monotonically increasing function of $a_{i}$ and $a_{j}$, respectively, we have a second symmetric equilibrium where each worker exerts effort $a_{\text {severe }}^{*}$ characterized by

$$
\frac{w_{H}+w_{L}}{2} p\left(a_{\text {severe }}^{*}\right)=h\left(a_{\text {severe }}^{*}\right) .
$$

In this scenario, equilibrium effort $a_{\text {severe }}^{*}$ increases in both the winner prize $w_{H}$ and the loser prize $w_{L} \cdot{ }^{9}$ From the workers' point of view, the equilibrium $\left(a_{\text {severe }}^{*}, a_{\text {severe }}^{*}\right)$ Pareto dominates the equilibrium where each worker chooses zero effort.

Comparing equilibrium efforts leads to the following result: ${ }^{10}$

Proposition 1 If $w_{L}$ is sufficiently small, equilibrium efforts follow the ranking $a_{\text {minor }}^{*}>$ $a_{\text {base }}^{*}>a_{\text {severe. }}^{*}$ In any case, we have $a_{\text {minor }}^{*}>a_{\text {base }}^{*}$.

Proof. First, compare $a_{\text {base }}^{*}$ with $a_{\text {minor }}^{*}$ described by (3) and (7), respectively. Since

$$
w_{H}-\frac{w_{H}+w_{L}}{2} p\left(a_{\text {minor }}^{*}\right)>\frac{1}{2}\left(w_{H}-w_{L}\right) \Leftrightarrow \frac{1}{2}\left(w_{H}+w_{L}\right)\left[1-p\left(a_{\text {minor }}^{*}\right)\right]>0
$$

is true and $h$ is monotonically increasing, we must have that $a_{\text {minor }}^{*}>a_{b a s e}^{*}$. Inspection of (3) and (11) shows that $a_{b a s e}^{*}>a_{\text {severe }}^{*}$, if and only if $w_{L}$ is smaller than the cut-off value $\bar{w}_{L} \in\left[0, w_{H}\right)$ described by

$$
\frac{1}{2}\left(w_{H}-\bar{w}_{L}\right)=\frac{w_{H}+\bar{w}_{L}}{2} p\left(a_{\text {severe }}^{*}\right) \Leftrightarrow \bar{w}_{L}=\frac{1-p\left(a_{\text {severe }}^{*}\right)}{1+p\left(a_{\text {severe }}^{*}\right)} w_{H} .
$$

As $a_{\text {minor }}^{*}$ and $a_{\text {base }}^{*}$ decrease in $w_{L}$, but $a_{\text {severe }}^{*}$ increases in $w_{L}$ there will be a clear ranking between the three equilibrium efforts if the influence of the loser prize $w_{L}$ can be ignored. In particular, given a zero loser prize $w_{L}$ efforts can be unambiguously ranked as $a_{\text {minor }}^{*}>$ $a_{\text {base }}^{*}>a_{\text {severe }}^{*}$. A comparison of worker $i$ 's objective functions for the three scenarios gives a first intuition for this ranking. If the department has been plunged into minor crisis, worker $i$ 's objective function misses the term $\frac{w_{H}+w_{L}}{2}\left(1-p\left(a_{i}\right)\right)\left(1-p\left(a_{j}\right)\right)$ compared to the baseline scenario. This term describes the fall back position of a worker in case of a joint failure. Not rewarding this outcome leads to higher incentives given a minor crisis. Similarly, if, given $w_{L}=0$, we switch from the baseline setting to the scenario of a severe crisis, worker $i$ 's objective function loses the term $w_{H} p\left(a_{i}\right)\left(1-p\left(a_{j}\right)\right)$. Hence, a worker is no longer rewarded for unilateral success which decreases individual incentives.

\footnotetext{
${ }^{9}$ Note that condition (1) can be rewritten as $\frac{d}{d a_{i}}\left(\frac{h\left(a_{i}\right)}{p\left(a_{i}\right)}\right)>0$.

${ }^{10}$ Since we focus on the impact of a crisis on work incentives, incomes $w_{L}$ and $w_{H}$ are exogenously given.
} 
A comparison of the reaction functions (5), (6), (9), and (10) leads to further insights. In case of a minor crisis (i.e., $\Pi \in(2 \underline{\pi}, \underline{\pi}+\bar{\pi}])$, tournament efforts are strategic substitutes in the sense of Bulow et al. (1985) so that more aggressive behavior by one worker decreases the activity level of the other worker. Since each worker wants to make use of this strategic effect, in equilibrium both end up in a situation with higher effort levels compared to the baseline scenario, where workers' optimal effort levels do not depend on each other: $a_{\text {minor }}^{*}>a_{\text {base }}^{*}$. However, if workers enter a state of severe crisis (i.e., $\Pi \in(\underline{\pi}+\bar{\pi}, 2 \bar{\pi}])$, tournament efforts are strategic complements: less effort by one worker induces less effort by the other. As both workers make use of this strategic effect, in equilibrium they behave less aggressively than in the baseline case: $a_{\text {severe }}^{*}<a_{\text {base. }}^{*}{ }^{11}$

Note that our framework serves as a basis for the following laboratory experiment on the impact of a crisis on individual incentives from relative performance pay. A comprehensive analysis of the optimal incentive scheme with endogenously chosen payments goes beyond the scope of this paper. Nevertheless, from the perspective of the company, the results indicate that incentives can be improved by supplementing a tournament scheme with a termination clause that leads to a collective dismissal of the members of a department if it does not exceed a certain moderate performance threshold.

\section{Experimental Design}

In our experiment, we tested the theoretical settings described above: a tournament with a negligible crisis (base), a minor crisis, or a severe crisis. All treatments consisted of a one-shot tournament between two players. Both contestants could either achieve state A (symbolizing $\bar{\pi}$ in the experiment) or state B (standing for $\underline{\pi}$ in the experiment), which affected the chances of winning the tournament as well as the likelihood to survive the crisis. The players simultaneously selected a number of points between zero and 100. The chosen points divided by 100 yield the probability of the player to achieve state A rather than state B in the experiment. For example, if a player chose 50 points his chance of ending up in state A was $50 \%$. Choosing a high number of points led to higher costs than choosing a smaller number. These costs were calculated as $c$ (points $)=\frac{200}{3}\left(\frac{\text { points }}{100}\right)^{3}$. In the experiment, we used the fictitious currency "taler," and the players received an initial endowment of 75 talers in all treatments. Having selected their number of points, all participants had to state their beliefs about the chosen points of their opponents. The question about beliefs was not announced in the instructions. The answer was not incentivized to prevent players from hedging their incomes by strategically announcing wrong beliefs. ${ }^{12}$ Information about the outcome of the tournament and the payoff was not revealed until the end of the experiment to prevent possible income effects on the answers to our control variables.

\footnotetext{
${ }^{11}$ Using a state-space formulation (e.g., $\pi=a+\theta$ like in Lazear and Rosen 1981) instead of the reduced-form representation of this paper leads qualitatively to the same outcome (see the "Additional Material, Part I"): for sufficiently low (high) values of the threshold $\Pi$, workers' efforts are strategic substitutes (complements).

${ }^{12}$ In two sessions for each treatment, we incentivized the beliefs and rewarded the players for a correct belief by paying 8 talers. If the belief deviated by 5 points from the selected effort, we paid 7.5 talers. A deviation of 10 points was rewarded with 6 talers and a deviation of 15 points with 3.5 talers. A higher deviation was not rewarded. We found no significant difference between incentivized and non-incentivized beliefs.
} 
To retrieve control variables for risk attitude, participants had to complete ten paired lottery choice decisions from Holt and Laury (2002), which were incentivized. Moreover, we used a simple set of lotteries proposed in Gächter et al. (2010) in order to measure loss aversion. Each player had to decide in six lotteries whether he wanted to participate in the lottery or not. With a $50 \%$ chance the players could win six talers while they had to pay between two and seven talers with a chance of $50 \%$. One of the lottery choices was selected for pay. ${ }^{13}$ All players answered a questionnaire containing questions on competitiveness (Smither and Houston, 1992), loss aversion, demographic details as well as open questions, where the decision about effort could be explained.

Corresponding to the theoretical settings we ran three treatments labeled "base," "minor," and "severe," respectively. The three treatments only differed in the department's termination probability. In the base-treatment, there was no risk of termination. Here, the player with the better performance received the winner prize of 100 talers while the loser received zero. Ties were broken randomly. Hence, if one player was in state A and the other in state B, the player in state A received 100 talers while the player in state B received zero talers. If both were in state $\mathrm{A}$ or both were in state $\mathrm{B}$, a random draw decided which player got the winner prize. In the minor-treatment, the setting was exactly the same but at least one player had to achieve state $\mathrm{A}$ in order to avoid termination. If both players were in state $\mathrm{B}$, they received zero talers. In contrast, both players had to achieve state $\mathrm{A}$ in the severe-treatment to avoid termination. If at least one player did not achieve state $\mathrm{A}$, both received nothing. If both were in state $\mathrm{A}$, a random draw decided who received the winner prize. Table 1 summarizes the experimental parameters and the resulting equilibrium predictions. For the computation of the equilibrium efforts $a_{\text {minor }}^{*}, a_{b a s e}^{*}$ and $a_{\text {severe }}^{*}$, we have to use our specifications $p\left(a_{i}\right)=a_{i}$ and $c\left(a_{i}\right)=\frac{200}{3} a_{i}^{3}$ together with the special values of winner and loser prizes (i.e., $w_{H}=100$ and $\left.w_{L}=0\right)$. Note that we set the loser prize equal to zero in order to guarantee a clear-cut analysis of the model. As pointed out above, a positive loser prize would lead to opposite incentives in the severe-treatment, on the one hand, and the minor- and base-treatments, on the other. In Section 8, we present experimental findings on the minor-treatment including positive loser prizes. The points in equilibrium presented in Table 1 are obtained by multiplying $a_{\text {minor }}^{*}, a_{b a s e}^{*}$ and $a_{\text {severe }}^{*}$ by 100 . In the experiment, each player chose discrete effort points from the set $\{0,5,10,15,20, \ldots, 100\}$. By allowing steps of five we reduced the complexity of the task while also securing to leave the players sufficient scope of action. The incremental steps of 5 points led to an additional equilibrium in the severe-treatment, where both players chose 20 . Note that this equilibrium as well as the equilibrium $(0,0)$ are Pareto dominated. We, therefore, concentrate our analysis on the equilibrium $(25,25)$. In all treatments, the costs of the chosen points were deducted from the participants' payoff.

At the outset of each session, all players were randomly assigned to a cubicle. The instructions were explained by the experimenter. ${ }^{14}$ We used neutral language throughout the experiment and avoided any value-ladden terms like "winner," "loser," "tournament prize," or "crisis." Before the experiment started, the participants completed a short quiz to check their

\footnotetext{
${ }^{13}$ Additionally, in two sessions of each treatment, we elicited ambiguity aversion following the approach of Trautmann et al. (2011).

${ }^{14}$ The instructions can be found in the "Additional Material, Part III."
} 
understanding of the instructions. The players also had the opportunity to ask clarifying questions. Communications among the participants were not allowed. The whole procedure took about 1.5 hours. On average, players earned 15.95 euro (approx. 20.26 USD at the time of the experiment) including a show-up fee of four euros. The exchange rate was one euro for eight talers. We conducted 9 sessions for each treatment with 24 players in each session. ${ }^{15}$ The players received information about the outcome of the tournament only at the end of the experiment.

\begin{tabular}{lccc}
\hline \hline Treatment & Base & Minor & Severe \\
\hline$w_{H}$ & 100 & 100 & 100 \\
$w_{L}$ & 0 & 0 & 0 \\
Termination & Never & Both players & At least one \\
Points in equilibrium & 50 & 60 & player in state B \\
\hline \hline
\end{tabular}

Table 1: Experimental parameters and the resulting equilibrium predictions

The experiment was conducted at the BonnEconLab, and the programming language was z-tree (Fischbacher, 2007). For recruiting we used the online system ORSEE (Greiner, 2004) Altogether 622 players participated in the experiment. As we employed a between-subjects one shot design, each player was allowed to attend one session only. All of the participants have been enrolled as students at the University of Bonn.

\section{Hypotheses}

At first sight, it is not clear how players will react to the crisis and the risk of collective dismissal. On the one hand, players may choose higher efforts compared to a standard tournament because they want to avoid states where their incomes are lost. On the other hand, in state of a crisis, the probability of being dismissed decreases expected income from winning compared to a standard tournament. Moreover, gaining survival of the department is a public good that is produced by both players together. These two effects can lead to effort levels that are lower than efforts in a standard tournament without collective dismissal.

The theoretical results of Section 4 show that we have obtained clear-cut results. Depending on whether effort choices are strategic substitutes - as in the minor-treatment - or strategic complements - as in the severe-treatment - players should choose higher or lower effort levels compared to the standard case without crisis. These results are summarized in Proposition 1 and tested as our first hypothesis, which uses the equilibrium results for the parameterized model displayed in the last row of Table 1:

Hypothesis 1: When deciding on efforts, players in the base-treatment will select 50 points, players in the minor-treatment will choose 60 points, and players in the severe-treatment 25 points.

\footnotetext{
${ }^{15}$ In some sessions we had fewer than 24 participants because some players did not show up.
} 
Previous experiments have shown that players tend to oversupply effort in tournament settings so that players may systematically deviate from the theoretical efforts in our experiment as well (Schotter and Weigelt, 1992). Nevertheless, Proposition 1 yields a clear ordinal ranking of equilibrium efforts, which should be maintained in the experiment even if there is systematic deviation toward higher effort levels in all treatments. The following hypothesis summarizes this claim:

Hypothesis 2: The selected effort levels are lowest in the severe-treatment and highest in the treatment labeled minor. Hence, we expect the following order of selected points on average: points severe-treatment $<$ points base-treatment $<$ points minor-treatment.

\section{Experimental Results}

We tested our hypotheses with data from the experiment starting with Hypothesis 1. As can already be seen in Figure 1, the average effort level in the base-treatment was 61.33, for the minor-treatment it was 66.50 , and in the severe-treatment we observed an average effort level of 55.45 points. All reported effort levels are significantly higher than the respective theoretical prediction (one sample mean comparison test: for all $p=0.000)^{16}$.

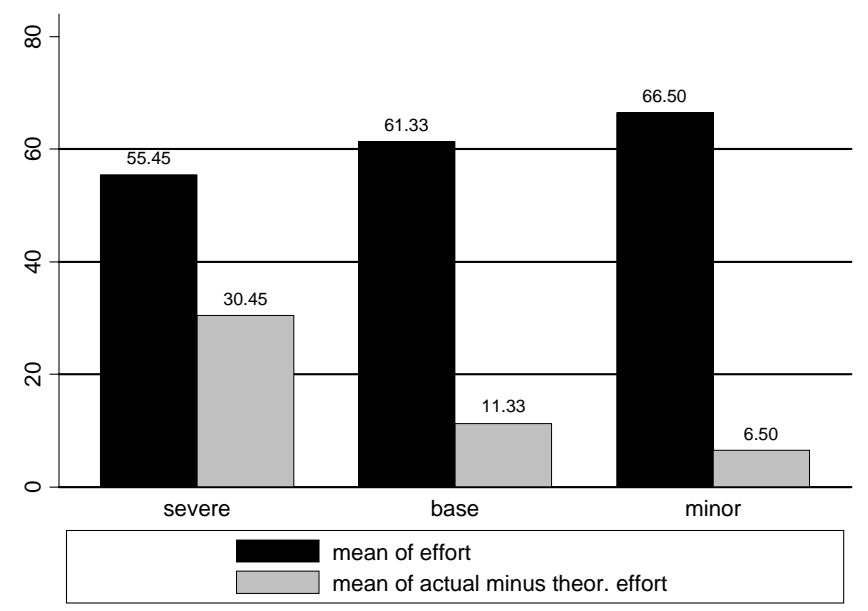

Figure 1: Mean of actual effort and difference of actual and theoretical effort by treatment

Hence, we have to reject Hypothesis 1. This finding is well in line with results from previous tournament experiments (see for example, Bull et al., 1987; Weigelt et al., 1989; Eriksson et al., 2009; or Price and Sheremeta 2011). However, the deviation from the theoretically predicted value is significantly larger in the severe-treatment than in the minor-, or base-treatment (see Figure 1 and pairwise Mann-Whitney-U tests: both $p=0.000)$. In fact, in the severe-treatment average effort exceeded the theoretical effort level by more than $122 \%$, which is a very high deviation compared to oversupply of effort in both the two other treatments and the findings in previous tournament experiments. This observation is even more remarkable when we take into

\footnotetext{
${ }^{16}$ Note that the same is true for the equilibria $(0,0)$ and $(20,20)$ in the severe-treatment.
} 
account that we used a cubic cost-of-effort function, whereas previous experiments typically applied only quadratic costs.

Oversupply of effort in the two crisis-treatments severe and minor has clear consequences for the survival rates of the department in the lab. These consequences are profound for the severetreatment. While the theoretically predicted probability of surviving is $\left(a_{\text {severe }}^{*}\right)^{2}=6.25 \%$ in the severe-treatment, it is five times higher in the experiment (30.75\%). In contrast, the department's survival probability in the minor-treatment is $88.78 \%$ in the experiment which is larger than the theoretical value of $2 a_{\text {minor }}^{*}\left(1-a_{\text {minor }}^{*}\right)+\left(a_{\text {minor }}^{*}\right)^{2}=84 \%$. Note that the oversupply of effort in the experiment is welfare increasing. To show this, we consider monetary welfare $W:=2(\bar{\pi} \cdot p(a)+\underline{\pi} \cdot(1-p(a))-c(a))$ and assume that the company has set a rational winner prize $w_{H}<\bar{\pi}-\underline{\pi}$ (i.e., incentive pay is smaller than the possible output increase from incentivizing workers). ${ }^{17}$ Then, in each treatment, experimental welfare is strictly larger than predicted equilibrium welfare (see the Appendix).

Result 1: In all treatments, players selected significantly higher effort levels than theoretically predicted. Hence, we have to reject Hypothesis 1. The deviation from the theoretical prediction in the severe-treatment was significantly larger than the deviation in the two other treatments.

To investigate Hypothesis 2, we check the ranking of efforts of the different treatments. The observation of Figure 1 indicates that the results support Hypothesis 2, which is confirmed by a Jonckheere-Trepstra Test (ascending order $p=0.000$ ) as well as pairwise two-sided MannWhitney-U tests (severe vs. base $p=0.028$, severe vs. minor $p=0.000$, and base vs. minor $p=0.062$ ). Further confirmation is provided by the regressions reported in Table 2. The dependent variable in all regressions is effort. We included dummy variables, which are 1 for the severe- resp. the minor-treatment and zero otherwise. Hence, the base-treatment serves as the reference category in these regressions. ${ }^{18}$ The results of the OLS regressions are reported in the first and second specification, but since our data are censored, we also use Tobit regressions and report our findings in the third and fourth column of Table 2. The results do not differ qualitatively. As expected, both dummies are significant and have the expected signs. Moreover, the coefficients of the treatment dummies are significantly different from each other. We also included several control variables for loss aversion, competitiveness, and demographic details in the regression. None of the control variables has a significant impact on the effort selected in the experiment. ${ }^{19}$

\footnotetext{
${ }^{17}$ Recall that each worker produces a minimum output $\underline{\pi}$ at zero cost.

${ }^{18}$ Note that the results are stable if we use the minor-treatment as a reference category.

${ }^{19}$ In Table A1 in the Appendix we report the results of the regressions when controlling for risk aversion instead of loss aversion. Since both measures are correlated we did not implement both in one regression. Note that the results are qualitatively the same.
} 


\begin{tabular}{lcccc}
\hline \hline & \multicolumn{2}{c}{ OLS } & \multicolumn{2}{c}{ Tobit } \\
& $(1)$ & $(2)$ & $(3)$ & $(4)$ \\
\hline Dummy severe-treatment & $-5.888^{* *}$ & $-5.806^{* *}$ & $-7.833^{* *}$ & $-7.799^{* *}$ \\
& $(2.648)$ & $(2.651)$ & $(3.197)$ & $(3.192)$ \\
Dummy minor-treatment & $5.167^{* *}$ & $5.053^{* *}$ & $5.580^{*}$ & $5.431^{*}$ \\
& $(2.464)$ & $(2.479)$ & $(3.013)$ & $(3.020)$ \\
Loss aversion & & 3.391 & & 3.735 \\
Competitiveness & & $(2.150)$ & & $(2.592)$ \\
& & 0.0991 & & 0.164 \\
Gender & & $(0.233)$ & & $(0.281)$ \\
& & 3.471 & & 3.968 \\
Dummy study economics & & $(2.185)$ & & $(2.647)$ \\
Constant & & -0.520 & & -1.173 \\
& $61.33^{* * *}$ & $57.13^{* * *}$ & $62.76^{* * *}$ & $57.54^{* * *}$ \\
\hline Observations & $(1.873)$ & $(3.737)$ & $(2.270)$ & $(4.539)$ \\
\# of left censored obs. & 622 & 622 & 622 & 622 \\
\# of right censored obs. & & & 42 & 42 \\
(Pseudo) $R^{2}$ & 0.03 & 0.04 & 71 & 71 \\
\hline \hline
\end{tabular}

Dependent variable is effort. Reference category is base.

Robust standard errors in parentheses. ${ }^{* * *} \mathrm{p}<0.01,{ }^{* *} \mathrm{p}<0.05,{ }^{*} \mathrm{p}<0.1$

Table 2: Comparison of effort between treatments

Result 2: The players correctly adjusted their efforts to the severity of the crisis. In the severe-treatment, the players selected significantly lower effort levels than in the minor-and the base-treatment. The highest effort levels were observed in the minor-treatment. Hence, the data support Hypothesis 2.

Since we also elicited the beliefs of the players about the chosen effort levels of their opponents, we were able to check if the players selected the optimal effort, given their belief. Figures 2,3 , and 4 show scatterplots of belief and chosen effort for all three treatments as well as the best response for a given belief, calculated according to the theoretical model discussed above. The reaction curve summarizes all these best responses for each treatment. In the severe-treatment, the reaction curve is increasing as efforts of both contestants are strategic complements, while the curve is decreasing in the minor-treatment, indicating strategic substitutes. Due to dominant strategies, the best response to every belief is 50 in the base-treatment. As could already be seen in Figures 2, 3, and 4, the correlations between chosen effort and belief are positive and significant for each treatment (Spearman's rank correlation: severe-treatment: $\rho=0.6704^{* * *}$, 
base-treatment: $\rho=0.5232^{* * *}$, minor-treatment: $\left.\rho=0.5323^{* * *}\right)$. Hence, regarding the baseand the minor-treatment, the findings are not in line with theory.

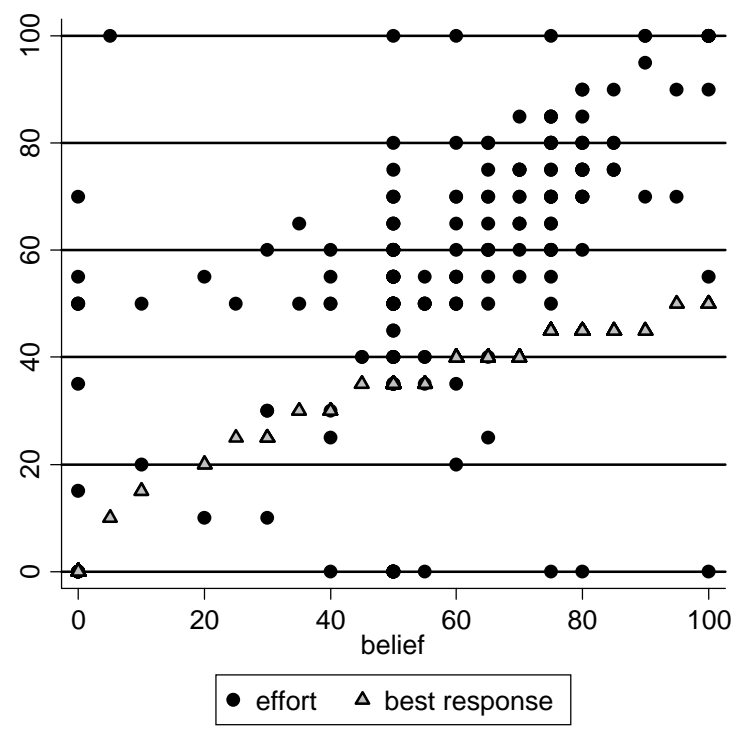

Figure 2: Scatterplot belief/effort and reaction curve for severe-treatment

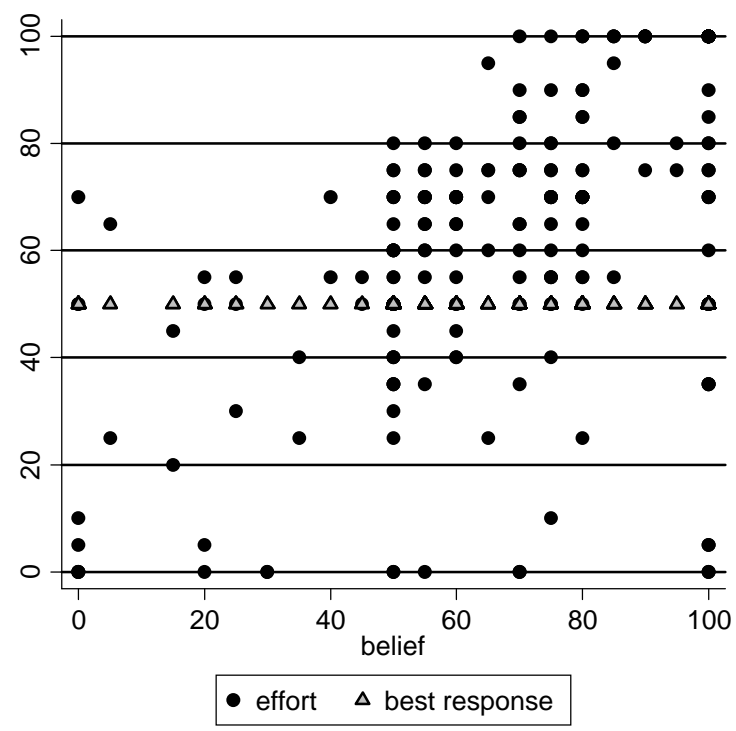

Figure 3: Scatterplot belief/effort and reaction curve for base-treatment 


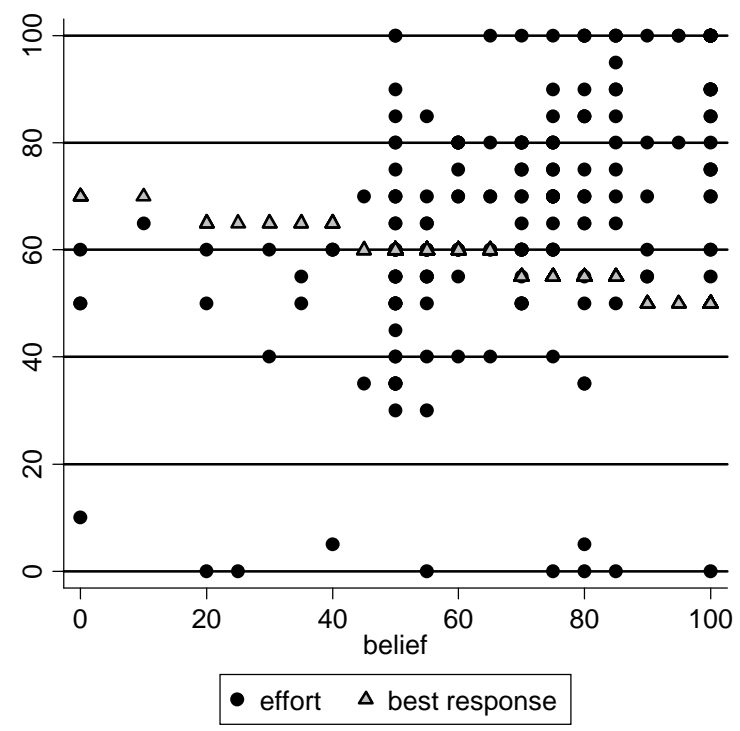

Figure 4: Scatterplot belief/effort and reaction curve for minor-treatment

Despite the last observation, the ranking of chosen efforts in the three treatments is perfectly in line with theory. In particular, players chose significantly more effort in the minor-treatment than in the severe-treatment, although best responses did not follow the interaction of strategic substitutes in the minor-treatment. The scatterplots in Figures 2 and 4 give a first hint why the observed relation and the theoretic relation between $a_{\text {severe }}^{*}$ and $a_{\text {minor }}^{*}$ coincide. As theoretically predicted, in the severe-treatment players' behavior followed the reactions of strategic complements. Hence, if a player anticipated high (low) effort of his opponent, he should also choose high (low) effort accordingly. As Figure 2 points out, the majority of players expected high efforts by the other players and correctly reacted by choosing high efforts as well. Actually, despite the winner-take-all outcome in case the department survives - one player receives $w_{H}$ whereas the other one earns zero - the two players seems to be in a team-like situation in the severe-treatment when struggling for the department's survival. Only if both players were successful and reached state A, could each one expect the positive payoff $w_{H} / 2$. Since most of the players expected their counterparts to be mainly interested in guaranteeing the department's survival, it was rational to work into the same direction. Nevertheless, players still chose significantly more effort in the minor-treatment. Recall that in the experiment, players' efforts followed strategic complements according to Spearman's rank correlation. Since more players had high effort beliefs in the minor-treatment than in the severe-treatment (166 players had effort beliefs of at least 50 points in the severe-treatment, whereas this number was 191 and, hence, significantly larger for the minor-treatment (Fisher-Test, $p=0.009)$ ), it is consequent that high effort levels were more often observed as complementary reactions in the minor-treatment than in the severe-treatment. There were two driving forces that led players to expect high efforts in the minor-treatment. First, both players were interested in preventing the termination of their department. Second, given survival of the department each player still had the chance to outperform his opponent, which was impossible in the case of a severe crisis. Thus, intuitively it seems plausible that more players had higher beliefs in the minor-treatment 
than in the severe-treatment.

However, the scatterplots should be interpreted carefully. First, we only have one observation of each player in the scatterplots. Second, as most players reported their opponent would select a high effort level, there is little information on how players react to low beliefs. Third, based on the Kolmogorov-Smirnov test, we have to reject the hypothesis that the theoretic reaction curve coincides with our data ( $p=0.000$ for all three treatments).

To sum up, our data are qualitatively in line with the theoretical results of Proposition 1. In particular, we found that the ranking between the effort levels of the three treatments matched our prediction. Two remarkable results should be emphasized, which both refer to the severetreatment: First, players supplied more than twice as much effort as theoretically predicted. Second, and related to the first issue, this doubling of exerted effort in the severe-treatment spills over to the department's survival probability, making it more than five times higher than in equilibrium. These two observations indicate that a crisis also has behavioral implications that are not completely covered by the model of Section 3, which assumes traditional textbook preferences for the contestants. We discuss possible explanations in the next section.

\section{Discussion}

In the severe-treatment players' efforts were more than twice as high compared to theory. This deviation from the equilibrium effort level is significantly larger than the deviations in the two other treatments and also larger than the deviations documented in other tournament experiments. In the following, we discuss possible explanations and link our findings to results from previous experiments.

Saving a department from termination has features of creating a public good in the minortreatment (for a positive loser prize) and the severe-treatment (for both zero and positive loser prizes). The extensive literature on public goods has shown that players tend to contribute even though this behavior is not rational (see for instance Ledyard, 1995, Palfrey and Prisbrey, 1997), which may correspond to observed oversupply of effort in the minor- and the severetreatments. However, in contrast to our setting, public good games do not have uncertain payments. A random component in collective payment can typically be found in situations with team-based compensation where less shirking and higher effort levels than predicted are observed in experiments as well (van Dijk et al., 2001, Vandegrift and Yavas, 2011). Our severetreatment indeed shows similarities with a team setting as both players had to be successful to avoid termination. However, our setting with relative performance pay also had a crucial difference to team pay. In contrast to a typical team setting where each team member receives a share of the generated output, our players participated in a winner-take-all tournament where only one of them earned the winner prize while the other received no payment. As the study of Irlenbusch and Ruchala (2008) shows, inducing a bonus payment for the highest contributor in a team-based compensation scheme reduced voluntary cooperation of the players and only enhanced effort if the bonus was sufficiently high. Hence, the study indicates that our payment structure will reduce the incentives to cooperate and to save the department in the severetreatment, which is in line with the effort ranking we observed. Nevertheless, this effect cannot 
explain the doubling of effort in the severe-treatment compared to the theoretical prediction.

Closer to our setting is the recent work of Babcock et al. (2011) who investigate social effects of team-based compensation in a real effort experiment. They compared an individual treatment with a team treatment. In both treatments, subjects had the opportunity to earn money if they visited the campus gym. In the individual treatment, they received two USD for each visit and a bonus of 25 USD if they went five or more times. Subjects were randomly matched with a "partner" in the team treatment. Each partner could also earn two USD for each visit of the gym but the bonus of 25 USD each was only paid if both subjects managed to visit the gym five or more times. The subjects had the opportunity to meet each other and communicate. Babcock et al. report that even though the risk of default in the team treatment was $43 \%$, the rate of bonus payments was nearly equal in both treatments. According to the authors, this observation can be explained with incentive effects of social interaction such as guilt, shame or altruism. Furthermore, self-control, precommitment or imitation might affect behavior. In contrast to this study, our players only played the game once and were not allowed to communicate. Additionally, only one player received a payment if the threshold was met. We nevertheless find that the players provided more effort than theoretically predicted. Hence, even in the absence of communication, working together to meet a threshold seems to motivate players.

Naturally, one might suspect that loss aversion of the players can explain our findings since in the minor- and the severe-treatments players lost their total incomes when the threshold was not met. However, introducing loss aversion in the benchmark model of Section 3 shows that, irrespective of whether players have exogenous or endogenous reference points, in the severe-treatment they should exert less effort compared to the benchmark model. ${ }^{20}$ This theoretical finding sharply contrasts with our observations in the experiment which document an excessive oversupply of effort. Note that the main feature of players' optimal efforts - being strategic substitutes in the minor-treatment and strategic complements in the severe-treatment - is preserved under loss aversion, which explains why optimal behavior strictly differs in the two treatments. Empirically, we controlled for the influence of loss aversion in our regressions in Table 2 which did not show a significant impact on effort. Also risk attitude and competitiveness did not have a significant effect on the players' effort choices, as documented by the regression results in Table 2 and Table A1 in the Appendix. Additionally, in two sessions of each treatment, we elicited ambiguity aversion following the approach of Trautmann et al. (2011) but found no difference regarding the effort choice of players that preferred the ambiguous urn and those who did not.

Consequently, we searched for an alternative theory that is in line with our empirical results and that may particularly explain the findings in the severe-treatment. Based on the feedback of the players in the lab, we suppose that players felt uncomfortable being confronted with a potential situation where zero income was paid out to both of them. Throughout the experiment, we used neutral language and did not label such a situation "termination of the department during a crisis," but the players clearly realized under which outcomes no one would earn the incomes $w_{L}$ and $w_{H}$. Therefore, we conjecture that players had negative feelings when

\footnotetext{
${ }^{20}$ See the "Additional Material, Part II".
} 
being confronted with the possibility of collectively losing $w_{L}+w_{H}$.

Technically, the players face a two-stage process. At the first stage, either the collective good "survival of the department" is produced or not. If the players succeed at the first stage, the collective good will be distributed at the second stage - the winner receives $w_{H}$ and the loser $w_{L}$. Hence, the well-being of each player is determined by a collective component at the first stage and an individual one at the second stage. Since the individual component is already incorporated into a player's objective function via the tournament payoffs, it remains to add the collective aspect. In order to proceed in this way, we subtract the function $\Lambda\left(w_{L}+w_{H}, P\right)$ from (2), (4), and (8), respectively. This function characterizes a player's negative feelings from the possible termination of the department and the collective loss of incentive pay, with $w_{L}+w_{H}$ describing the collective loss in this case and $P$ the probability of collective dismissal, which depends on the given treatment. We assume that $\Lambda\left(w_{L}+w_{H}, 0\right)=0$ (i.e., negative feelings become zero if termination is impossible so that the players do not face a threat any longer). Furthermore, $\Lambda\left(w_{L}+w_{H}, P\right)$ is assumed to be monotonically increasing in both arguments (i.e., $\Lambda_{1}, \Lambda_{2}>0$ : the higher the collective loss in case of termination and the more likely this event, the stronger will be a player's negative feelings from the threat of a department closure), with $\Lambda_{11}, \Lambda_{22} \geq 0$. Note that $P$ decreases in the players' efforts, which allows for the natural reaction of human beings to threats, namely to strain oneself to reduce the negative feelings (e.g., Elster, 1998).

Let $\hat{a}_{t}^{*}$ denote the equilibrium effort of the players in treatment $t \in\{$ base, minor, severe $\}$ under the new objective function, which incorporates negative feelings $\Lambda$. If players value monetary income more strongly than their negative feelings, these efforts compare as follows (see the Appendix):

$$
\hat{a}_{\text {minor }}^{*}>\hat{a}_{\text {base }}^{*}>\hat{a}_{\text {severe }}^{*} .
$$

This ranking coincides with the ranking of observed average efforts in our experiment. The data emphasized that players deviated from predicted effort more strongly in the severe-treatment than in the minor-treatment. In fact, chosen effort was more than twice as high in the severetreatment compared to the equilibrium effort level, but in the minor-treatment players only realized efforts that exceeded the theoretical value by about 11 percent. In the Appendix, we show that introducing negative feelings $\Lambda$ leads to extra incentives in both the severe- and minor-treatment, but under a generally high level of chosen efforts - which is documented for all treatments - the effort-enhancing effect of $\Lambda\left(w_{L}+w_{H}, P\right)$ is clearly stronger in the severetreatment. Intuitively, when effort is chosen the marginal benefit of reducing one's own negative feelings, $\partial \Lambda\left(w_{L}+w_{H}, P\right) / \partial a_{i}$, determines the extra incentives from crisis. Since this marginal benefit increases in the effort level of co-workers in the severe-treatment and decreases in the efforts of co-workers in the minor-treatment, introducing negative feelings $\Lambda$ into the benchmark model can explain the observed puzzle because efforts as well as effort beliefs are high in the two crisis treatments (see Figures 2 and 4 ).

In order to test our new theoretical approach, we ran additional treatments with a positive loser prize $w_{L}>0$. These treatments have the further advantage that a player's income from losing a tournament now strictly differs from the zero income following collective dismissal. In the benchmark model of Section 3, we show that $a_{\text {severe }}^{*}$ increases in $w_{L}$, but $a_{\text {minor }}^{*}$ decreases 
in $w_{L}$. From the results reported in the appendix, we know that extra incentives from reducing negative feelings $\Lambda$ increase in $w_{L}$ in both the severe-treatment and the minor-treatment. ${ }^{21}$ Testing the severe-treatment with a positive loser prize is, therefore, not informative at all: if effort increases compared to average effort under a zero loser prize, this finding will be in line with both the benchmark model and the new approach; if effort decreases, this result would contradict both theoretical settings. However, if introducing a positive loser prize into the minor-treatment yields larger or equal efforts compared to the setting with a zero loser prize, such a finding would contradict the benchmark model and be in line with our new approach. For these reasons, we used the minor-treatment instead of the severe-treatment as a starting point to test the new theoretical setting.

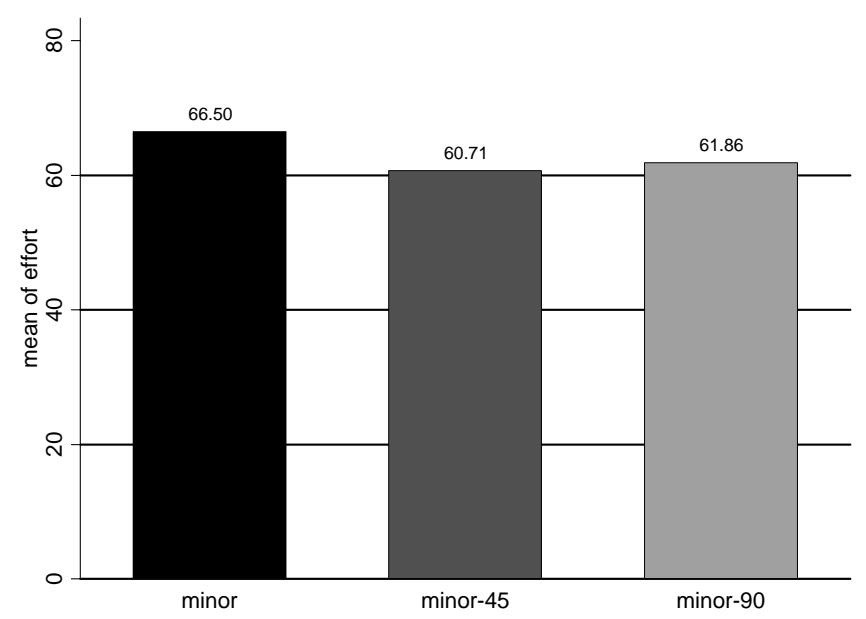

Figure 5: Mean of effort in the minor-treatments

We designed two treatments labeled minor- 45 and minor-90, which are similar to the minortreatment. The only change is that we introduced a positive loser prize of 45 talers in the minor-45 and of 90 talers in the minor-90 treatment. Both prizes were only paid to the loser of the tournament if at least one player was in state A so that the department was not terminated. Following the benchmark model, the equilibrium effort level is 55 points for the minor- 45 and 50 points for the minor-90 treatment. We conducted three sessions for each treatment at the BonnEconLab. The setup was similar to the other treatments described above. The results of the additional treatments as well as those of the original minor-treatment are depicted in Figure 5. A pairwise comparison of the efforts of the three treatments does not show a significant difference (Mann-Whitney-U test). This result is supported by the regressions reported in Table 3. Again, effort is the dependent variable, and we control for loss aversion, competitiveness, and demographic details. The reference category is the minor-45-treatment, and we included dummy variables for the minor- and the minor-90 treatment. As expected, the dummy variables are not significant in the full specifications. ${ }^{22}$ Note that we observe a weakly significant difference between the minor- and the minor-45-treatments if we only have the treatment dummies in the regression. However, this effect is not robust and not supported by nonparametric tests.

\footnotetext{
${ }^{21}$ Let $\partial^{2} \Lambda\left(w_{L}+w_{H}, P\right) / \partial a_{i} \partial w_{L}$ denote the mixed partial derivative with respect to effort and loser prize. In the appendix, we see that this derivative is positive for the minor-treatment as well as for the severe-treatment in equations (12) and (14), respectively.

${ }^{22}$ We also did regressions where we controlled for the risk attitudes and found qualitatively similar results.
} 
Hence, the players did not reduce effort significantly if positive loser prizes were paid. Even if the loser prize was close to the size of the winner prize (minor-90 treatment), which sharply cuts incentives in the benchmark model, the players did not reduce effort levels.

\begin{tabular}{lcccc}
\hline \hline & \multicolumn{2}{c}{ OLS } & \multicolumn{2}{c}{ Tobit } \\
& $(1)$ & $(2)$ & $(3)$ & $(4)$ \\
\hline Dummy minor & $5.786^{*}$ & 5.486 & $6.768^{*}$ & 6.295 \\
& $(3.466)$ & $(3.513)$ & $(3.798)$ & $(3.839)$ \\
Dummy minor-90 & 1.161 & 1.066 & 1.071 & 0.948 \\
& $(4.140)$ & $(4.138)$ & $(4.524)$ & $(4.496)$ \\
Loss aversion & & -0.918 & & -1.164 \\
& & $(2.571)$ & & $(2.939)$ \\
Competitiveness & & -0.121 & & -0.0562 \\
& & $(0.293)$ & & $(0.344)$ \\
Gender & & 1.549 & & 2.669 \\
& & $(2.810)$ & & $(3.222)$ \\
Dummy study economics & & 0.568 & & -0.119 \\
Constant & & $(2.966)$ & & $(3.278)$ \\
& $60.71^{* * *}$ & $61.75^{* * *}$ & $61.27^{* * *}$ & $61.32^{* * *}$ \\
\hline Observations & $(3.073)$ & $(5.025)$ & $(3.273)$ & $(5.638)$ \\
\# left censored obs. & 352 & 352 & 352 & 352 \\
\# of right censored obs. & & & 11 & 11 \\
(Pseudo) $R^{2}$ & 0.012 & 0.014 & 0.002 & 0.002 \\
\hline \hline
\end{tabular}

Dependent variable is effort. Reference category is minor- 45 .

Robust standard errors in parentheses. ${ }^{* * *} \mathrm{p}<0.01,{ }^{* *} \mathrm{p}<0.05,{ }^{*} \mathrm{p}<0.1$

Table 3: Comparison of effort between treatments

To summarize, our findings are not in line with the prediction of the benchmark model of Section 3. According to that model, the introduction of positive loser prizes should lead to a considerable decline of efforts. Such decline is a well-known stylized fact from previous tournament experiments and field studies without crisis (see, e.g., Ehrenberg and Bognanno, 1990b,a; Lynch, 2005; and Harbring and Lünser 2008). However, our findings sharply contrast with this prediction. They support the reasoning of our new approach: since efforts in the three minor-treatments did not significantly differ, the introduction of a positive loser prize had two opposing effects, which just offset each other. The loser prize $w_{L}=45$ decreased the prize spread $w_{H}-w_{L}$, which partly destroyed standard tournament incentives. At the same time, $w_{L}$ boosted incentives to reduce negative feelings $\Lambda\left(w_{L}+w_{H}, P\right)$ from the threat of collective dismissal. The data indicate that both effects nearly compensated each other. Further increasing the loser prize to $w_{L}=90$ in the minor-90 treatment did not lead to significantly different effort levels compared 
to the minor-treatment with zero loser prize. Here, standard tournament incentives were even lower than in minor-45, but additional incentives via $\Lambda\left(w_{L}+w_{H}, P\right)$ increased further. Again, both effects nearly offset each another. In this situation, standard tournament incentives become negligible as the gain from winning, given by the prize spread $w_{H}-w_{L}=10$, is only worth 1.25 euro. Nevertheless, average effort even slightly increased compared to minor-45, which shows that incentives via $\Lambda$ will be important if the stakes are rather high (i.e., incomes at risk, $w_{L}+w_{H}=190$, corresponding to 23.75 euro, are large).

\section{Conclusion}

The theoretical and experimental results of our paper have shown that the severity of a crisis significantly influences worker behavior. The theoretical part of the paper shows that effort choices are strategic complements given a severe crisis, yielding rather poor incentives for the workers compared to a situation without crisis. However, efforts are strategic substitutes and highest if the workers experience a minor crisis. Our experimental findings confirm the expected effort ranking for the three scenarios. The experiment also points to a puzzle: workers' effort choices deviated significantly stronger from equilibrium behavior under a severe crisis than under a minor crisis or in the absence of a crisis. This deviation influenced the department's survival probability, making it five times higher than predicted under a severe crisis. Since findings from previous experiments studying team-based pay and models incorporating loss aversion cannot explain the empirical puzzle, we conjecture that the anticipated possibility of collective dismissal led to negative feelings for the workers. In order to decrease these feelings, they chose more effort compared to a setting with standard textbook preferences.

We tested the alternative approach on negative feelings by running two additional treatments. In the three initial treatments base, minor, and severe we normalized the loser prize to zero and considered a winner-take-all contest. In the two additional treatments, we introduced a - low respectively high - positive loser prize into the initial setting of a minor crisis. The resulting average efforts did not significantly differ from the average effort in the minor-treatment with zero loser prize. Even if the loser prize became so large that the tournament prize spread was negligible, incentives did not significantly differ from the initial winner-take-all treatment. These observations are in line with the negative-feelings approach, where direct monetary incentives via the prize spread are replaced by incentives to guarantee the department's survival and thus, to protect workers' collective wage bill. Our finding has a clear implication for the wage policy of a company. Introducing prizes for tournament losers has positive incentive effects under the shadow of crisis, which clearly differs from behavior in tournaments without collective dismissal as well as predicted behavior under a minor crisis and standard textbook preferences. However, since monetary incentives and incentives from crisis just offset each other, it is still optimal for the company to save labor costs and withdraw loser prizes. Hence, a wage policy that induces high-powered incentives via relative performance pay is still optimal under the shadow of crisis as long as typical negative implications of corporate tournaments such as sabotaging and influence activities do not become too intense.

Our experimental findings have a further implication for the personnel policy of a company. 
In a bad economic situation, in which a department has a positive likelihood of being terminated, employees will struggle to guarantee survival of the department rather than to give up or free ride. Hence, the management should not be afraid that an initially small crisis or even the rumor on a possible crisis will end up with the department being dissolved. On the contrary, it seems realistic that if a department faces a difficult situation, this will make the employees stick together and supply additional effort to protect their collective incomes. In other words, a crisis and the possibility of collective dismissal may strengthen group coherence among the workforce.

\section{Appendix}

\section{Experimental welfare versus predicted equilibrium welfare}

Given the specification used in the experiment, monetary welfare reads as

$$
W=2 \cdot\left(\bar{\pi} a+(1-a) \underline{\pi}-\frac{200}{3} a^{3}\right)=2 \cdot\left(\underline{\pi}+\Delta \pi a-\frac{200}{3} a^{3}\right)
$$

with $\Delta \pi:=\bar{\pi}-\underline{\pi}$ and $a$ being workers' efforts. Let $W_{t}^{e q u}$ denote equilibrium welfare in treatment $t \in\{$ base, minor, severe $\}$ and $W_{t}^{e x p}$ the respective experimental welfare. Using the equilibrium efforts from Table 1 to compute $W_{t}^{\text {equ }}$ and experimental means from Figure 1 to compute $W_{t}^{\text {exp }}$ yields the following results:

\begin{tabular}{lccc}
\hline \hline$t$ & $W_{t}^{\text {equ }}$ & $W_{t}^{\text {exp }}$ & $W_{t}^{\text {exp }}>W_{t}^{\text {equ }}$ if \\
\hline base & $2(\underline{\pi}+0.5 \Delta \pi-8 . \overline{3})$ & $2(\underline{\pi}+0.6133 \Delta \pi-15.38)$ & $\Delta \pi>62.49$ \\
minor & $2(\underline{\pi}+0.6 \Delta \pi-14.4)$ & $2(\underline{\pi}+0.665 \Delta \pi-19.61)$ & $\Delta \pi>80.15$ \\
& & & \\
severe & $2(\underline{\pi}+0.25 \Delta \pi-1.04)$ & $2(\underline{\pi}+0.5545 \Delta \pi-11.37)$ & $\Delta \pi>33.92$ \\
\hline \hline
\end{tabular}

At first sight, a direct comparison between $W_{t}^{e q u}$ and $W_{t}^{\text {exp }}$ seems impossible, because output levels $\bar{\pi}$ and $\underline{\pi}$ were not part of the experiment. However, a rational company that uses relative performance pay would not offer a winner prize $w_{H}=100$ - the value used in the experiment that exceeds the possible increase of output induced by the incentive scheme. In other words, we must have $w_{H}=100<\Delta \pi$ so that all conditions in the last column are satisfied. 


\section{Effort choices}

\begin{tabular}{lcc}
\hline \hline & OLS & Tobit \\
& $(1)$ & $(2)$ \\
\hline Dummy severe-treatment & $-5.795^{* *}$ & $-7.771^{* *}$ \\
& $(2.654)$ & $(3.195)$ \\
Dummy minor-treatment & $5.164^{* *}$ & $5.561^{*}$ \\
& $(2.471)$ & $(3.014)$ \\
\# of safe choices (H\&L) & -0.202 & -0.140 \\
& $(0.539)$ & $(0.648)$ \\
Competitiveness & 0.128 & 0.199 \\
& $(0.234)$ & $(0.282)$ \\
Gender & 3.165 & 3.618 \\
& $(2.169)$ & $(2.624)$ \\
Dummy study economics & -0.365 & -1.019 \\
& $(2.497)$ & $(2.939)$ \\
Constant & $59.27^{* * *}$ & $59.42^{* * *}$ \\
& $(4.901)$ & $(5.935)$ \\
\hline Observations & 622 & 622 \\
\# of left censored obs. & & 42 \\
\# of right censored obs. & & 71 \\
(Pseudo) $R^{2}$ & 0.04 & 0.004 \\
\hline \hline
\end{tabular}

Dependent variable is effort. Reference category is base.

Robust standard errors in parentheses. ${ }^{* * *} \mathrm{p}<0.01,{ }^{* *} \mathrm{p}<0.05,{ }^{*} \mathrm{p}<0.1$

Table A1: Comparison of effort between treatments controlling for risk aversion 


\section{Negative Feelings $\Lambda$ from the Threat of Collective Dismissal}

In the base-treatment, subtracting $\Lambda\left(w_{L}+w_{H}, 0\right)$ from the previous objective function (2) does not alter the equilibrium effort. Hence, both workers are again expected to exert effort $a_{\text {base }}^{*}=: \hat{a}_{\text {base }}^{*}$, being described by (3).

In the minor-treatment, we have $P=\left(1-p\left(a_{i}\right)\right)\left(1-p\left(a_{j}\right)\right)$ so that the modified objective function of worker $i$,

$$
\begin{aligned}
& w_{H} p\left(a_{i}\right)\left(1-p\left(a_{j}\right)\right)+\frac{w_{H}+w_{L}}{2} p\left(a_{i}\right) p\left(a_{j}\right)+w_{L} p\left(a_{j}\right)\left(1-p\left(a_{i}\right)\right) \\
& -c\left(a_{i}\right)-\Lambda\left(w_{L}+w_{H},\left(1-p\left(a_{i}\right)\right)\left(1-p\left(a_{j}\right)\right)\right)
\end{aligned}
$$

yields the first-order condition

$$
w_{H}-\frac{w_{H}+w_{L}}{2} p\left(a_{j}\right)+\Lambda_{2}\left(w_{L}+w_{H},\left(1-p\left(a_{i}\right)\right)\left(1-p\left(a_{j}\right)\right)\right)\left(1-p\left(a_{j}\right)\right)=h\left(a_{i}\right)
$$

with $\Lambda_{2}(\cdot, \cdot)$ describing the derivative of function $\Lambda(\cdot, \cdot)$ with respect to its second argument. Let $\hat{a}_{\text {minor }}^{*}$ denote a worker's effort choice in the corresponding symmetric equilibrium with

$$
w_{H}-\frac{w_{H}+w_{L}}{2} p\left(\hat{a}_{\text {minor }}^{*}\right)+\Lambda_{2}\left(w_{L}+w_{H},\left(1-p\left(\hat{a}_{\text {minor }}^{*}\right)\right)^{2}\right)\left(1-p\left(\hat{a}_{\text {minor }}^{*}\right)\right)=h\left(\hat{a}_{\text {minor }}^{*}\right) .
$$

Comparison with (7) immediately shows that $\hat{a}_{\text {minor }}^{*}>a_{\text {minor }}^{*}$, due to the additional positive term at the left-hand side of (13) and the fact that the left-hand (right-hand) side of (13) monotonically decreases (increases) in $\hat{a}_{\text {minor }}^{*}$. (Recall that $\Lambda_{22} \geq 0$.)

In the severe-treatment, worker $i$ maximizes

$$
\frac{w_{H}+w_{L}}{2} p\left(a_{i}\right) p\left(a_{j}\right)-c\left(a_{i}\right)-\Lambda\left(w_{L}+w_{H}, 1-p\left(a_{i}\right) p\left(a_{j}\right)\right) .
$$

By using the first-order condition

$$
\frac{w_{H}+w_{L}}{2} p\left(a_{j}\right)+\Lambda_{2}\left(w_{L}+w_{H}, 1-p\left(a_{i}\right) p\left(a_{j}\right)\right) p\left(a_{j}\right)=h\left(a_{i}\right)
$$

the symmetric equilibrium $\left(a_{i}, a_{j}\right)=\left(\hat{a}_{\text {severe }}^{*}, \hat{a}_{\text {severe }}^{*}\right)$ can be characterized via

$$
\frac{w_{H}+w_{L}}{2} p\left(\hat{a}_{\text {severe }}^{*}\right)+\Lambda_{2}\left(w_{L}+w_{H}, 1-p\left(\hat{a}_{\text {severe }}^{*}\right)^{2}\right) p\left(\hat{a}_{\text {severe }}^{*}\right)=h\left(\hat{a}_{\text {severe }}^{*}\right) .
$$

Comparing (11) and (15) shows that $\hat{a}_{\text {severe }}^{*}>a_{\text {severe }}^{*}$ : (11) can be rewritten as

$$
\frac{w_{H}+w_{L}}{2}=\frac{h\left(a_{\text {severe }}^{*}\right)}{p\left(a_{\text {severe }}^{*}\right)}
$$

with the right-hand side monotonically increasing in $a_{\text {severe }}^{*}$ due to (1). Rewriting (15) yields

$$
\frac{w_{H}+w_{L}}{2}+\Lambda_{2}\left(w_{L}+w_{H}, 1-p\left(\hat{a}_{\text {severe }}^{*}\right)^{2}\right)=\frac{h\left(\hat{a}_{\text {severe }}^{*}\right)}{p\left(\hat{a}_{\text {severe }}^{*}\right)}
$$

with the left-hand side monotonically decreasing in $\hat{a}_{\text {severe }}^{*}$ because of $\Lambda_{22} \geq 0$, whereas the righthand side monotonically increases in $\hat{a}_{\text {severe }}^{*}$ due to (1). Since the left-hand side of equation (17) 
differs from the left-hand side of (16) by the positive term $\Lambda_{2}\left(w_{L}+w_{H}, 1-p\left(\hat{a}_{\text {severe }}^{*}\right)^{2}\right)$, the relation $\hat{a}_{\text {severe }}^{*}>a_{\text {severe }}^{*}$ must be true.

When comparing the three equilibrium efforts under negative feelings $\Lambda$ for our setting with a zero loser prize, we immediately obtain $\hat{a}_{\text {minor }}^{*}>\hat{a}_{\text {base }}^{*}$. Equilibrium efforts in the basetreatment are still larger than in the severe-treatment if standard monetary incentives have a higher impact on the players' effort choices than negative feelings. This can be seen by inspection of the left-hand sides of (3) and (15) with $w_{L}=0$ :

$$
\Lambda_{2}\left(w_{H}, 1-p\left(\hat{a}_{\text {severe }}^{*}\right)^{2}\right) p\left(\hat{a}_{\text {severe }}^{*}\right)<\left(1-p\left(\hat{a}_{\text {severe }}^{*}\right)\right) \frac{w_{H}}{2} .
$$

Since direct monetary income should be more relevant for a player than second-order feelings of uneasiness due to crisis, it seems plausible that the inequality is satisfied, implying $\hat{a}_{\text {base }}^{*}>$ $\hat{a}_{\text {severe }}^{*}$.

The findings of our experiment emphasize that players' average effort exceeded the respective equilibrium effort of the benchmark model (see Section 4) considerably more in the severe-treatment than in the minor-treatment. This major puzzle can be explained by our new theoretical approach, if the introduction of $\Lambda\left(w_{H}, P\right)$ into the players' objective functions shifts efforts more upwards in the severe-treatment than in the minor-treatment. The comparison of (13) and (15) indicates that negative feelings $\Lambda$ have a higher impact in the severe-treatment than in the minor-treatment if

$$
\Lambda_{2}\left(w_{H}, 1-p\left(\hat{a}_{\text {severe }}^{*}\right)^{2}\right) p\left(\hat{a}_{\text {severe }}^{*}\right)>\Lambda_{2}\left(w_{H},\left(1-p\left(\hat{a}_{\text {minor }}^{*}\right)\right)^{2}\right)\left(1-p\left(\hat{a}_{\text {minor }}^{*}\right)\right) .
$$

Since realized values of $p\left(a_{i}\right)=a_{i}$ were typically higher than 0.5 in all treatments and players chose higher efforts in the minor-treatment than in the severe-treatment, we have $p\left(\hat{a}_{\text {severe }}^{*}\right)>$ $\left(1-p\left(\hat{a}_{\text {minor }}^{*}\right)\right)$. Moreover, $\hat{a}_{\text {minor }}^{*}>\hat{a}_{\text {severe }}^{*}$ leads to

$$
\Lambda_{2}\left(w_{H}, 1-p\left(\hat{a}_{\text {severe }}^{*}\right)^{2}\right) \geq \Lambda_{2}\left(w_{H},\left(1-p\left(\hat{a}_{\text {minor }}^{*}\right)\right)^{2}\right)
$$

because $\Lambda_{22} \geq 0$, and

$$
1-p\left(\hat{a}_{\text {severe }}^{*}\right)^{2}>\left(1-p\left(\hat{a}_{\text {minor }}^{*}\right)\right)^{2} \Leftrightarrow 2 p\left(\hat{a}_{\text {minor }}^{*}\right)>p\left(\hat{a}_{\text {minor }}^{*}\right)^{2}+p\left(\hat{a}_{\text {severe }}^{*}\right)^{2}
$$

is true for $\hat{a}_{\text {minor }}^{*}>\hat{a}_{\text {severe }}^{*}$.

Note that extra incentives due to $\Lambda$ that are larger in the severe-treatment than in the minor-treatment do not crucially depend on $\hat{a}_{\text {minor }}^{*}>\hat{a}_{\text {severe }}^{*}$ but on the generally high effort levels in the two crisis treatments. In fact, recall that the probabilities of collective dismissal are differently formed in both treatments. In the minor-treatment, we have $P=$ $\left(1-p\left(a_{i}\right)\right)\left(1-p\left(a_{j}\right)\right)$. Differentiating with respect to $a_{i}$ gives

$$
\frac{\partial P}{\partial a_{i}}=-p^{\prime}\left(a_{i}\right)\left(1-p\left(a_{j}\right)\right)
$$

Thus, if in the minor-treatment co-worker $j$ already chooses considerable effort, worker $i$ 's impact on the reduction of $P$ and, therefore, on reducing his negative feelings $\Lambda$ will be rather 
low. This effect decreases worker $i$ 's incentives to avoid termination of the department. This argumentation holds for both workers and explains the rather limited effect of negative feelings on incentives in the minor-treatment. Technically, this effect can be recognized most clearly in the last term on the left-hand side of the first-order condition $(12), 1-p\left(a_{j}\right)$, which is rather small for high values of $a_{j}$. However, in the severe-treatment we have just the opposite effect. Here, the probability of collective dismissal reads as $P=1-p\left(a_{i}\right) p\left(a_{j}\right)$, with

$$
\frac{\partial P}{\partial a_{i}}=-p^{\prime}\left(a_{i}\right) p\left(a_{j}\right)
$$

Hence, in the severe-treatment worker $i$ 's impact on the reduction of the dismissal probability increases in co-worker $j$ 's effort level $a_{j}$. Consequently, under high chosen efforts and high effort beliefs in the two crisis treatments (see Figures 2 and 4) workers have strong incentives to exert effort in order to reduce their negative feelings in the severe-treatment. This effect is shown by the last term on the left-hand side of the first-order condition $(14), p\left(a_{j}\right)$, which is rather large, given a high value of $a_{j}$.

In order to exemplarily illustrate individual behavior under negative feelings $\Lambda$, let

$$
\Lambda\left(w_{L}+w_{H}, P\right)=\alpha \cdot\left(w_{L}+w_{H}\right)+\beta \cdot P, \quad \alpha, \beta \in(0,1)
$$

with the two weights $\alpha$ and $\beta$ measuring the workers' degree of negative feelings for the two dimensions "monetary income" and "collective dismissal."23 Together with our parameterized functions in the experiment described by $p\left(a_{i}\right)=a_{i}$ as well as $c\left(a_{i}\right)=\frac{200}{3} a_{i}^{3}$ and $w_{L}=0$, we obtain

$$
\begin{aligned}
\hat{a}_{\text {minor }}^{*} & =\frac{1}{800}\left(\sqrt{\left(2 \beta+w_{H}\right)^{2}+3200\left(\beta+w_{H}\right)}-w_{H}-2 \beta\right) \\
\text { and } \quad \hat{a}_{\text {severe }}^{*} & =\frac{1}{200}\left(\frac{w_{H}}{2}+\beta\right)
\end{aligned}
$$

as equilibrium effort levels, which both lie in the interval $(0,1)$ in the given setting with $w_{H}=$ 100. Moreover, it is easy to check that $\hat{a}_{\text {minor }}^{*}>\hat{a}_{\text {base }}^{*}>\hat{a}_{\text {severe }}^{*}$ holds. We finally have to show that the introduction of $\Lambda$ increases equilibrium efforts more strongly in the severe-treatment than in the minor-treatment, that is

$$
\hat{a}_{\text {severe }}^{*}-a_{\text {severe }}^{*}>\hat{a}_{\text {minor }}^{*}-a_{\text {minor }}^{*}
$$

with $a_{\text {severe }}^{*}=0.25$ and $a_{\text {minor }}^{*}=(\sqrt{33}-1) / 8 \approx 0.6$. Inserting for the equilibrium efforts and $w_{H}=100$ in condition (19) and rearranging yields $4 \beta(2 \beta+75 \sqrt{33}-225)>0$, which is clearly satisfied. Hence, in our example we can explicitly show that extra incentives from negative feelings due to the threat of collective dismissal are stronger under a severe crisis than under a minor crisis.

\footnotetext{
${ }^{23} \alpha$ and $\beta$ being smaller than one indicates that monetary incomes are more important for individuals than negative feelings.
} 


\section{References}

Altmann, S., Falk, A. and Wibral, M. (2012): Promotions and Incentives: The Case of MultiStage Elimination Tournaments. Journal of Labor Economics, 30, pp. 149-174.

Babcock, P, Bedard, K., Charness, G., Harman, J. and Royer, H. (2011): Letting Down the Team? - Social Effects of Team Incentives. Working Paper.

Berkovitch, E. and Israel, R. (1996): The Design of Internal Control and Capital Structure. Review of Financial Studies, 9, pp. 209-240.

Berkowitz, M. K. and Kotowitz, Y. (1993): Promotions as Work Incentives. Economic Inquiry, 31, pp. 342-353.

Bernhardt, D. and Mongrain, S. (2010): The Layoff Rat Race. Scandinavian Journal of Economics, 112, pp. 185-210.

Bewley, T. (1999): Why Wages Don’t Fall During a Recession. Harvard University Press.

Boyle, M. (2001): Performance Reviews: Perilous Curves Ahead. Fortune, May 15, pp. 187-188.

Bull, C., Schotter, A. and Weigelt, K. (1987): Tournaments and Piece Rates: An Experimental Study. Journal of Political Economy, 95, pp. 1-33.

Bulow, J. I., Geanakoplos, J. D. and Klemperer, P. D. (1985): Multimarket Oligopoly: Strategic Substitutes and Complements. Journal of Political Economy, 93, pp. 488-511.

Cason, T. N., Sheremeta, R. and Zhang, J. (2012): Communication and Efficiency in Competitive Coordination Games. Games and Economic Behavior, 76, pp. 26-43.

Dewatripont, M. and Tirole, J. (1994): A Theory of Debt and Equity: Diversity of Securities and Manager-Shareholder Congruence. Quarterly Journal of Economics, 109, pp. 1027-1054.

Ehrenberg, R. G. and Bognanno, M. L. (1990a): Do Tournaments Have Incentive Effects? Journal of Political Economy, 98, pp. 1307-1324.

Ehrenberg, R. G. and Bognanno, M. L. (1990b): The Incentive Effects of Tournaments Revisited: Evidence from the European PGA Tour. Industrial and Labor Relations Review, Special Issue 43, pp. 74-S-88-S.

Elster, J. (1998): Emotions and Economic Theory. Journal of Economic Literature, 36, pp. $47-74$.

Eriksson, T., Teyssier, S. and Villeval, M.-C. (2009): Self Selection and the Efficiency of Tournaments. Economic Inquiry, 47, pp. 530-548.

Fischbacher, U. (2007): z-Tree - Zurich Toolbox for Readymade Economic Experiments. Experimental Economics, 10, pp. 171-178.

Friebel, G. and Matros, A. (2005): A Note on CEO Compensation, Elimination Tournaments and Bankruptcy Risk. Economics of Governance, 6, pp. 105-111. 
Garvey, G. and Swan, P. L. (1992a): Managerial Objectives, Capital Structure, and the Provision of Worker Incentives. Journal of Labor Economics, 10, pp. 357-379.

Garvey, G. and Swan, P. L. (1992b): Optimal Capital Structure for a Hierarchical Firm. Journal of Financial Intermediation, 2, pp. 376-400.

Gaston, N. (1997): Efficiency Wages, Managerial Discretion, and the Fear of Bankruptcy. Journal of Economic Behavior \& Organization, 33, pp. 41-59.

Glassner, V. and Galgoczi, B. (2009): Plant-Level Responses to the Economic Crisis in Europe. Working Paper.

Green, J. R. and Stokey, N. L. (1983): A Comparison of Tournaments and Contracts. Journal of Political Economy, 91, pp. 349-364.

Greiner, B. (2004): An Online Recruitment System for Economic Experiments. In: Kremer, K. and Macho, V. (Ed.) Forschung und wissenschaftliches Rechnen, GWDG Bericht 63, Göttingen: Gesellschaft für Wissenschaftliche Datenverarbeitung, pp. 79-93.

Grossman, S. J. and Hart, O. D. (1982): Corporate Financial Structure and Managerial Incentives. In: Economics of Information and Uncertainty, McCall, J., pp. 107-140.

Gächter, S., Johnson, E. J. and Herrmann, A. (2010): Individual-Level Loss Aversion in Riskless and Risky Choices. CeDEx Discussion Paper No. 2010-20.

Hansson, M. and Wigblad, R. (2006): Pyrrhic Victories - Anticipating the Closedown Effect. International Journal of Human Resource Management, 17, pp. 938-958.

Harbring, C. and Irlenbusch, B. (2011): Sabotage in Tournaments: Evidence from a Laboratory Experiment. Management Science, 57, pp. 611-627.

Harbring, C. and Lünser, G. (2008): On the Competition of Asymmetric Agents. German Economic Review, 9, pp. 373-395.

Hart, O. D. (1995): Firms, Contracts and Financial Structure. Oxford University Press.

Hart, O. D. and Holmstrom, B. (1987): The Theory of Contracts. Bewley, T., Cambridge, Cambridge University Press.

Holt, C. A. and Laury, S. K. (2002): Risk Aversion and Incentive Effects. American Economic Review, 92, pp. 1644-1655.

Irlenbusch, B. and Ruchala, G. K. (2008): Relative Rewards within Team-based Compensation. Labour Economics, 15, pp. 141-167.

Lazear, E. P. and Rosen, S. (1981): Rank-Order Tournaments as Optimum Labor Contracts. Journal of Political Economy, 89, pp. 841-864.

Ledyard, J. O. (1995): Handbook of Experimental Economics, Chapter Public Goods: A Survey of Experimental Research. Princeton University Press, pp. 111-194. 
Lynch, J.G. (2005): The Effort Effects of Prizes in the Second Half of Tournaments. Journal of Economic Behavior \& Organization, 57, pp. 115-129.

Malcomson, J. M. (1984): Work Incentives, Hierarchy, and Internal Labor Markets. Journal of Political Economy, 92, pp. 486-507.

Nalebuff, B. J. and Stiglitz, J. E. (1983): Prizes and Incentives: Towards a General Theory of Compensation and Competition. Bell Journal of Economics, 14, pp. 21-43.

O'Keeffe, M., Viscusi, W. K. and Zeckhauser, R. (1984): Economic Contests: Comparative Reward Schemes. Journal of Labor Economics, 2, pp. 27-56.

Orrison, A., Schotter, A. and Weigelt, K. (2004): Multiperson Tournaments: An Experimental Examination. Management Science, 50, pp. 268-279.

Palfrey, T. R. and Prisbrey, J. E. (1997): Anomalous Behavior in Public Goods Experiments: How Much and Why? American Economic Review, 87, pp. 829-846.

Price, C.R. and Sheremeta, R.M (2011): Endowment Effects in Contests. Economics Letters, 111, pp. 217-219.

Rosen, S. (1986): Prizes and Incentives in Elimination Tournaments. American Economic Review, 76, pp. 701-715.

Santos Pinto, L. (2010): Positive Self-Image in Tournaments. International Economic Review, 51 , pp. $475-496$.

Schmidt, K. M. (1997): Managerial Incentives and Product Market Competition. Review of Economic Studies, 64, pp. 191-213.

Schotter, A. and Weigelt, K. (1992): Asymmetric Tournaments, Equal Opportunity Laws, and Affirmative Action: Some Experimental Results. Quarterly Journal of Economics, 107, pp. $511-539$.

Sheremeta, R.M. and Zhang, J. (2010): Can Groups Solve the Problem of Over-Bidding in Contests? Social Choice and Welfare, 35, pp. 175-197.

Smither, R. D. and Houston, J. M. (1992): The Nature of Competitiveness: The Development and Validation of the Competitiveness Index. Educational and Psychological Measurement, 52 , pp. 407-418.

Sverke, M., Hellgren, J. and Näswall, K. (2002): No Security: A Meta-Analysis and Review of Job Insecurity and Its Consequences. Journal of Occupational Health Psychology, 7, pp. 242-264.

Trautmann, St. T., Vieider, F.M. and Wakker, P.P. (2011): Preference Reversals for Ambiguity Aversion. Management Science, 7, pp. 1320-1333.

van Dijk, F., Sonnemans, J. and van Winden, F. (2001): Incentive Systems in a Real Effort Experiment. European Economic Review, 45, pp. 187-214. 
Vandegrift, D. and Yavas, A. (2011): An Experimental Test of Behavior under Team Production. Managerial and Decision Economics, 32, pp. 35-51.

Vandegrift, D., Yavas, A. and Brown, P. (2007): Incentive Effects and Overcrowding in Tournaments: An Experimental Analysis. Experimental Economics, 10, pp. 345-368.

Weigelt, K., Dukerich, J. and Schotter, A. (1989): Reactions to Discrimination in an Incentive Pay Compensation Scheme: A Game-theoretic Approach. Organizational Behavior and Human Decision Processes, 44, pp. 26-44.

Zabojník, J. and Bernhardt, D. (2001): Corporate Tournaments, Human Capital Acquisition, and the Firm Size-Wage Relation. Review of Economic Studies, 68, pp. 693-716. 


\section{Additional Material for \\ "Relative Performance Pay in the Shadow of Crisis"}

\section{Part I: State-space formulation with strategic substitutes and complements}

Let worker $i$ 's $(i=1,2)$ output be described by

$$
\pi_{i}=a_{i}+\theta_{i}
$$

Here, $a_{i}$ denotes effort and $\theta_{i}$ either luck or unknown ability. Whereas $a_{i}$ is endogenously chosen by worker $i$, the realization of $\theta_{i}$ is exogenously given. Following Lazear and Rosen (1981), $\theta_{1}$ and $\theta_{2}$ are assumed to be independent and identically distributed with density $f$ and cdf $F$. Let $f$ be unimodal and symmetric about zero. ${ }^{1}$ Effort costs are described by the convex function $c\left(a_{i}\right)$. Let $\Pi$ denote the critical output that must be at least realized by the two workers to achieve their incomes $w_{L}$ and $w_{H}$. We assume that the tournament winner receives income $w_{H}=w>0$ and the tournament loser $w_{L}=0$.

In the given setting, worker $i$ maximizes expected utility

$$
E U_{i}\left(a_{i}\right)=w \cdot P\left(a_{i}, a_{j}\right)-c\left(a_{i}\right)
$$

with

$$
\begin{aligned}
P\left(a_{i}, a_{j}\right) & =P\left(a_{i}+\theta_{i}>a_{j}+\theta_{j} \wedge a_{i}+\theta_{i}+a_{j}+\theta_{j}>\Pi\right) \\
& =P\left(\theta_{i}>a_{j}-a_{i}+\theta_{j} \wedge \theta_{i}>\Pi-a_{i}-a_{j}-\theta_{j}\right) \\
& =P\left(\theta_{i}>\max \left\{a_{j}-a_{i}+\theta_{j}, \Pi-a_{i}-a_{j}-\theta_{j}\right\}\right) \\
& =\int_{-\infty}^{\infty}\left(\int_{\max \left\{a_{j}-a_{i}+\theta_{j}, \Pi-a_{i}-a_{j}-\theta_{j}\right\}}^{\infty} f(\alpha) d \alpha\right) f\left(\theta_{j}\right) d \theta_{j}
\end{aligned}
$$

We assume that an equilibrium in pure strategies exists and is characterized by the first-order conditions $^{2}$

$$
E U_{i}^{\prime}\left(a_{i}\right)=w \cdot \frac{\partial P\left(a_{i}, a_{j}\right)}{\partial a_{i}}-c^{\prime}\left(a_{i}\right)=0 \quad(i=1,2) .
$$

Implicit differentiation yields

$$
\frac{\partial a_{i}}{\partial a_{j}}=-\frac{w \cdot \frac{\partial^{2} P\left(a_{i}, a_{j}\right)}{\partial a_{i} \partial a_{j}}}{E U_{i}^{\prime \prime}\left(a_{i}\right)}
$$

Since $E U_{i}^{\prime \prime}\left(a_{i}\right)<0$ by the second-order condition, we have

$$
\operatorname{sign}\left(\frac{\partial a_{i}}{\partial a_{j}}\right)=\operatorname{sign}\left(\frac{\partial^{2} P\left(a_{i}, a_{j}\right)}{\partial a_{i} \partial a_{j}}\right) \text {. }
$$

If $\frac{\partial^{2} P\left(a_{i}, a_{j}\right)}{\partial a_{i} \partial a_{j}}>(<) 0$, the workers' efforts are strategic complements (substitutes).

Note that applying Leibniz's formula leads to

$$
\begin{aligned}
\frac{\partial P}{\partial a_{i}} & =\int_{-\infty}^{\infty} \frac{\partial}{\partial a_{i}}\left(\int_{\max \left\{a_{j}-a_{i}+\theta_{j}, \Pi-a_{i}-a_{j}-\theta_{j}\right\}}^{\infty} f(\alpha) d \alpha\right) f\left(\theta_{j}\right) d \theta_{j} \\
& =\int_{-\infty}^{\infty} f\left(\max \left\{a_{j}-a_{i}+\theta_{j}, \Pi-a_{i}-a_{j}-\theta_{j}\right\}\right) f\left(\theta_{j}\right) d \theta_{j} .
\end{aligned}
$$

\footnotetext{
${ }^{1}$ Unimodality is often assumed in tournament models; see, e.g., Dixit (1987), Drago, Garvey and Turnbull (1996), Hvide (2002), Chen (2003).

${ }^{2}$ The problem that the existence of pure-strategy equilibria cannot be guaranteed in general is well-known in the tournament literature; see, e.g., Lazear and Rosen (1981), p. 845, Nalebuff and Stiglitz (1983), p. 29. See Schöttner (2008) and Gürtler (2011) for sufficient conditions that guarantee existence. Usually, the existence of a pure-strategy equilibrium is assumed for the Lazear-Rosen tournament game. This equilibrium is then characterized. We procede in the same way.
} 
We have $a_{j}-a_{i}+\theta_{j} \gtreqless \Pi-a_{i}-a_{j}-\theta_{j} \Leftrightarrow \theta_{j} \gtreqless \frac{\Pi}{2}-a_{j}$ so that $\partial P / \partial a_{i}$ can be written as

$$
\frac{\partial P}{\partial a_{i}}=\int_{-\infty}^{\frac{\Pi}{2}-a_{j}} f\left(\Pi-a_{i}-a_{j}-\theta_{j}\right) f\left(\theta_{j}\right) d \theta_{j}+\int_{\frac{\Pi}{2}-a_{j}}^{\infty} f\left(a_{j}-a_{i}+\theta_{j}\right) f\left(\theta_{j}\right) d \theta_{j} .
$$

By again applying Leibniz's formula we obtain

$$
\begin{aligned}
\frac{\partial^{2} P\left(a_{i}, a_{j}\right)}{\partial a_{i} \partial a_{j}}= & -f\left(\Pi-a_{i}-a_{j}-\left(\frac{\Pi}{2}-a_{j}\right)\right) f\left(\frac{\Pi}{2}-a_{j}\right) \\
& -\int_{-\infty}^{\frac{\Pi}{2}-a_{j}} f^{\prime}\left(\Pi-a_{i}-a_{j}-\theta_{j}\right) f\left(\theta_{j}\right) d \theta_{j} \\
& +f\left(a_{j}-a_{i}+\left(\frac{\Pi}{2}-a_{j}\right)\right) f\left(\frac{\Pi}{2}-a_{j}\right) \\
& +\int_{\frac{\Pi}{2}-a_{j}}^{\infty} f^{\prime}\left(a_{j}-a_{i}+\theta_{j}\right) f\left(\theta_{j}\right) d \theta_{j} \\
= & -\int_{-\infty}^{\frac{\Pi}{2}-a_{j}} f^{\prime}\left(\Pi-a_{i}-a_{j}-\theta_{j}\right) f\left(\theta_{j}\right) d \theta_{j} \\
& +\int_{\frac{\Pi}{2}-a_{j}}^{\infty} f^{\prime}\left(a_{j}-a_{i}+\theta_{j}\right) f\left(\theta_{j}\right) d \theta_{j} .
\end{aligned}
$$

Following Nalebuff and Stiglitz (1983, pp. 26-27) by restricting the analysis to the case of symmetric equilibria with $a_{i}=a_{j}=a$ yields $^{3}$

$$
\frac{\partial^{2} P\left(a_{i}, a_{j}\right)}{\partial a_{i} \partial a_{j}}=-\int_{-\infty}^{\frac{\Pi}{2}-a} f^{\prime}\left(\Pi-2 a-\theta_{j}\right) f\left(\theta_{j}\right) d \theta_{j}+\int_{\frac{\Pi}{2}-a}^{\infty} f^{\prime}\left(\theta_{j}\right) f\left(\theta_{j}\right) d \theta_{j} .
$$

When considering the first expression at the right-hand side of equation $(*)$, note that $f^{\prime}(x)>(<) 0$ if $x<(>) 0$ due to the unimodality of $f$. Since $\theta_{j}<\frac{\Pi}{2}-a \Leftrightarrow \Pi-2 a>2 \theta_{j}$ holds for

$$
-\int_{-\infty}^{\frac{\Pi}{2}-a} f^{\prime}\left(\Pi-2 a-\theta_{j}\right) f\left(\theta_{j}\right) d \theta_{j}
$$

all arguments of the derivative $f^{\prime}\left(\Pi-2 a-\theta_{j}\right)$ are positive in the relevant range so that $f^{\prime}\left(\Pi-2 a-\theta_{j}\right)$ exclusively takes negative values. Thus,

$$
-\int_{-\infty}^{\frac{\Pi}{2}-a} f^{\prime}\left(\Pi-2 a-\theta_{j}\right) f\left(\theta_{j}\right) d \theta_{j}>0
$$

Concerning the second expression at the right-hand side of $\left(^{*}\right)$, integration by parts gives

$$
\begin{aligned}
\int_{-\infty}^{\infty} f^{\prime}\left(\theta_{j}\right) f\left(\theta_{j}\right) d \theta_{j} & =\left.f\left(\theta_{j}\right)^{2}\right|_{-\infty} ^{\infty}-\int_{-\infty}^{\infty} f\left(\theta_{j}\right) f^{\prime}\left(\theta_{j}\right) d \theta_{j} \\
& \Leftrightarrow \int_{-\infty}^{\infty} f^{\prime}\left(\theta_{j}\right) f\left(\theta_{j}\right) d \theta_{j}=0 .
\end{aligned}
$$

Since $f^{\prime}\left(\theta_{j}\right) f\left(\theta_{j}\right)=-f^{\prime}\left(-\theta_{j}\right) f\left(-\theta_{j}\right), \forall \theta_{j}$, and $f^{\prime}\left(\theta_{j}\right) f\left(\theta_{j}\right)>(<) 0$ for $\theta_{j}<(>) 0$ we must have that

$$
\int_{\frac{\Pi}{2}-a}^{\infty} f^{\prime}\left(\theta_{j}\right) f\left(\theta_{j}\right) d \theta_{j}<\int_{-\infty}^{\infty} f^{\prime}\left(\theta_{j}\right) f\left(\theta_{j}\right) d \theta_{j}=0 .
$$

\footnotetext{
${ }^{3}$ Since workers are completely homogeneous, symmetric equilibria seem to be the most plausible ones. However, we cannot rule out the existence of additional asymmetric equilibria. Note that for the standard Lazear-Rosen (1981) model only a unique symmetric equilibrium exists.
} 
To sum up, $\partial^{2} P\left(a_{i}, a_{j}\right) / \partial a_{i} \partial a_{j}$ - described by equation $\left(^{*}\right)$ - consists of two integrals, the first being unambiguously positive and the second unambiguously negative. The first integral vanishes if $\Pi \rightarrow-\infty$, implying $\partial^{2} P\left(a_{i}, a_{j}\right) / \partial a_{i} \partial a_{j}<0$. Hence, in this situation workers' efforts are strategic substitutes. The second integral vanishes if $\Pi \rightarrow \infty$, implying $\partial^{2} P\left(a_{i}, a_{j}\right) / \partial a_{i}$ $\partial a_{j}>0$. In that situation, workers' efforts are strategic complements. Therefore, similarly to the simple setting used in the paper for the lab experiment, the standard Lazear-Rosen framework also yields that a low (high) value of $\Pi$ - i.e., a minor (severe) crisis - is associated with efforts being strategic substitutes (complements).

\section{Part II: Loss aversion}

In the following, we show that incorporating loss aversion in our benchmark model does not help to explain excessive effort provision in the severe-treatment.

Loss aversion can become particularly important for players should situations arise where their incomes are lost, although they invested a very large effort and, hence, are not responsible for the loss. In the given setting, there are situations in which players lose their incomes due to the termination of the department. In addition, there are situations where both players realize a high output so that the tournament winner is determined by tossing a fair coin. Again, a player is not responsible for losing the winner prize in these circumstances. Recall that we controlled for loss aversion in our regressions (see Table 2) and did not find a significant influence. However, we could only test loss aversion in a fairly general context without a concrete reference point. We applied the test by Gaechter et al. (2010), who cautiously state that their procedure "arguably" measures loss aversion. ${ }^{4}$ In the next step, we will introduce loss aversion into our benchmark model - first, based on an exogenous reference income, and thereafter letting the reference point be formed endogenously.

Suppose that players in the experiment compared their realized incomes (i.e., $w_{H}$ or $w_{L}$ ) with an exogenously given reference income $Y^{R} \in\left(w_{L}, w_{H}\right)$. For example, since players are homogeneous, they will typically end up in a symmetric equilibrium where each one has a winning probability of $1 / 2$. Anticipating this tournament outcome, the average income $Y^{R}=$ $\left(w_{H}+w_{L}\right) / 2$ seems to be a natural candidate for the reference point. Following Barberis et al. (2001), DeMeza and Webb (2007), p. 70, and Gill and Stone (2010), we assume that a loss averse player's preferences can be described by a linearly kinked utility function: ${ }^{5}$

$$
U(Y)= \begin{cases}Y+g \cdot\left(Y-Y^{R}\right) & \text { if } \quad Y>Y^{R} \\ Y+l \cdot\left(Y-Y^{R}\right) & \text { if } \quad Y \leq Y^{R}\end{cases}
$$

with $Y \in\left\{w_{H}, w_{L}\right\}$ as a player's realized tournament income. The parameters $g$ and $l$ indicate the players' weighing of relative gains and losses, respectively. We assume $0<g<l<1$ so that losses are more important than gains, but each player mostly cares for his absolute income, which can directly used for consumption purposes.

In the base-treatment, player $i$ maximizes $^{6}$

$$
\begin{aligned}
& \left(p\left(a_{i}\right)\left(1-p\left(a_{j}\right)\right)+\frac{p\left(a_{i}\right) p\left(a_{j}\right)}{2}+\frac{\left(1-p\left(a_{i}\right)\right)\left(1-p\left(a_{j}\right)\right)}{2}\right)\left(w_{H}+g\left(w_{H}-Y^{R}\right)\right) \\
& +\left(p\left(a_{j}\right)\left(1-p\left(a_{i}\right)\right)+\frac{p\left(a_{i}\right) p\left(a_{j}\right)}{2}+\frac{\left(1-p\left(a_{i}\right)\right)\left(1-p\left(a_{j}\right)\right)}{2}\right)\left(w_{L}+l\left(w_{L}-Y^{R}\right)\right)-c\left(a_{i}\right) .
\end{aligned}
$$

\footnotetext{
${ }^{4}$ Additionally, we also asked two questions about loss aversion in the questionnaire. As the answers are correlated with each other and with the measure of Gaechter et al. (2010), we can only add one of it to the regressions. None of the measures has a significant impact on effort provision.

${ }^{5}$ Preferences based on reference points and loss aversion are described by the prospect theory introduced by Kahneman and Tversky (1979). See Tversky and Kahneman (1991) especially on loss aversion.

${ }^{6}$ As in the benchmark model, the tournament winner will be chosen by a fair coin toss if both players have realized identical outputs.
} 
Rearranging the first-order condition ${ }^{7}$ leads to optimal effort $\tilde{a}_{b a s e}^{*}$, being described by

$$
\frac{1}{2}\left[\left(w_{H}+g\left(w_{H}-Y^{R}\right)\right)-\left(w_{L}+l\left(w_{L}-Y^{R}\right)\right)\right]=h\left(\tilde{a}_{b a s e}^{*}\right) .
$$

Note that for $w_{L}=0$, as in the experiment, this effort is larger than in the benchmark model (i.e., $\tilde{a}_{\text {base }}^{*}>a_{\text {base }}^{*}$ ).

In the minor-treatment, player $i$ 's objective function reads as

$$
\begin{aligned}
& \left(p\left(a_{i}\right)\left(1-p\left(a_{j}\right)\right)+\frac{p\left(a_{i}\right) p\left(a_{j}\right)}{2}\right)\left(w_{H}+g\left(w_{H}-Y^{R}\right)\right) \\
& +\left(p\left(a_{j}\right)\left(1-p\left(a_{i}\right)\right)+\frac{p\left(a_{i}\right) p\left(a_{j}\right)}{2}\right)\left(w_{L}+l\left(w_{L}-Y^{R}\right)\right)-c\left(a_{i}\right) .
\end{aligned}
$$

The first-order condition yields

$$
\left(w_{H}+g\left(w_{H}-Y^{R}\right)\right)-\frac{p\left(a_{j}\right)}{2}\left[w_{H}+g\left(w_{H}-Y^{R}\right)+w_{L}+l\left(w_{L}-Y^{R}\right)\right]=h\left(a_{i}\right) .
$$

As in the benchmark model, efforts are strategic substitutes. Both players' reaction curves intersect in a unique and symmetric equilibrium $\left(\tilde{a}_{i}^{*}, \tilde{a}_{j}^{*}\right)=\left(\tilde{a}_{\text {minor }}^{*}, \tilde{a}_{\text {minor }}^{*}\right)$ being implicitly described by

$$
\left(w_{H}+g\left(w_{H}-Y^{R}\right)\right)-\frac{p\left(\tilde{a}_{\text {minor }}^{*}\right)}{2}\left[w_{H}+g\left(w_{H}-Y^{R}\right)+w_{L}+l\left(w_{L}-Y^{R}\right)\right]=h\left(\tilde{a}_{\text {minor }}^{*}\right) .
$$

Since

$$
\frac{\partial \tilde{a}_{\text {minor }}^{*}}{\partial l}=\frac{\frac{p\left(\tilde{a}_{\text {minor }}^{*}\right)}{2}\left(Y^{R}-w_{L}\right)}{\frac{p^{\prime}\left(\tilde{a}_{\text {minor }}^{*}\right)}{2}\left[w_{H}+g\left(w_{H}-Y^{R}\right)+w_{L}+l\left(w_{L}-Y^{R}\right)\right]+h^{\prime}\left(\tilde{a}_{\text {minor }}^{*}\right)}>0,
$$

equilibrium efforts increase in the degree of loss aversion, which is in line with our experimental findings for the minor-treatment. When comparing $\tilde{a}_{\text {minor }}^{*}$ and $\tilde{a}_{\text {base }}^{*}$ for $w_{L}=0$, i.e.,

$$
\begin{gathered}
\left(w_{H}+g\left(w_{H}-Y^{R}\right)\right)-\frac{p\left(\tilde{a}_{\text {minor }}^{*}\right)}{2}\left[(1+g) w_{H}-(l+g) Y^{R}\right]=h\left(\tilde{a}_{\text {minor }}^{*}\right) \\
\text { and } \frac{1}{2}\left[(1+g) w_{H}+(l-g) Y^{R}\right]=h\left(\tilde{a}_{\text {base }}^{*}\right)
\end{gathered}
$$

we find that $\tilde{a}_{\text {minor }}^{*}>\tilde{a}_{\text {base }}^{*}$, since

$$
\begin{gathered}
\left(w_{H}+g\left(w_{H}-Y^{R}\right)\right)-\frac{p\left(\tilde{a}_{\text {minor }}^{*}\right)}{2}\left[(1+g) w_{H}-(l+g) Y^{R}\right]>\frac{1}{2}\left[(1+g) w_{H}+(l-g) Y^{R}\right] \\
\Leftrightarrow p\left(\tilde{a}_{\text {minor }}^{*}\right)<1
\end{gathered}
$$

is true.

Finally, we have to analyze the outcome of the severe-treatment under loss aversion. Player $i$ maximizes

$$
\left(\frac{p\left(a_{i}\right) p\left(a_{j}\right)}{2}\right)\left(w_{H}+g\left(w_{H}-Y^{R}\right)\right)+\left(\frac{p\left(a_{i}\right) p\left(a_{j}\right)}{2}\right)\left(w_{L}+l\left(w_{L}-Y^{R}\right)\right)-c\left(a_{i}\right) .
$$

There are two equilibria. In the first one, both players choose zero effort: if one player realizes the low output for sure, termination of the department cannot be precluded any longer so that

\footnotetext{
${ }^{7}$ The second-order condition will be satisfied if $\left(w_{H}+g\left(w_{H}-Y^{R}\right)\right)-\left(w_{L}+l\left(w_{L}-Y^{R}\right)\right)>0$. In the experiment with $w_{L}=0$, this condition always holds. When $w_{L}>0$, the condition is satisfied if, for example, $Y^{R}=\left(w_{H}+w_{L}\right) / 2$.
} 
the other player optimally minimizes effort costs by choosing zero effort as well. The second equilibrium is characterized by the players' first-order conditions ${ }^{8}$

$$
\frac{p\left(a_{j}\right)}{2}\left[w_{H}+g\left(w_{H}-Y^{R}\right)+w_{L}+l\left(w_{L}-Y^{R}\right)\right]=h\left(a_{i}\right) .
$$

Thus, efforts are strategic complements, as in the benchmark model. Since, in equilibrium, $h\left(a_{i}\right) / p\left(a_{j}\right)=h\left(a_{j}\right) / p\left(a_{i}\right)=\left[w_{H}+g\left(w_{H}-Y^{R}\right)+w_{L}+l\left(w_{L}-Y^{R}\right)\right] / 2$ players choose identical efforts, being implicitly described by

$$
\frac{w_{H}+g\left(w_{H}-Y^{R}\right)+w_{L}+l\left(w_{L}-Y^{R}\right)}{2}=\frac{h\left(\tilde{a}_{\text {severe }}^{*}\right)}{p\left(\tilde{a}_{\text {severe }}^{*}\right)} .
$$

Note that the right-hand side is strictly increasing in $\tilde{a}_{\text {severe }}^{*}$. However, the left-hand side decreases in the degree of loss aversion, $l$, since $w_{L}<Y^{R}$. Hence, loss aversion reduces incentives in the severe-treatment. Alternatively, we can directly compare $\tilde{a}_{\text {severe }}^{*}$ given $Y^{R}=\left(w_{H}+w_{L}\right) / 2$ with equilibrium effort in the benchmark model, $a_{\text {severe }}^{*}$. Because

$$
\frac{w_{H}+g\left(w_{H}-Y^{R}\right)+w_{L}+l\left(w_{L}-Y^{R}\right)}{2}<\frac{w_{H}+w_{L}}{2} \Leftrightarrow-\frac{1}{4}\left(w_{H}-w_{L}\right)(l-g)<0
$$

is true, we obtain $\tilde{a}_{\text {severe }}^{*}<a_{\text {severe }}^{*}$. At last, we can compare $\tilde{a}_{\text {severe }}^{*}$ and $\tilde{a}_{\text {base }}^{*}$ under $w_{L}=0$. Since $p\left(\tilde{a}_{\text {severe }}^{*}\right)<1$, a sufficient condition for $\tilde{a}_{\text {base }}^{*}>\tilde{a}_{\text {severe }}^{*}$ is

$$
\frac{1}{2}\left[(1+g) w_{H}+(l-g) Y^{R}\right]>\frac{w_{H}+g\left(w_{H}-Y^{R}\right)-l Y^{R}}{2} \Leftrightarrow l Y^{R}>0,
$$

which is true.

Altogether, introducing loss aversion into the benchmark model preserves the ranking of equilibrium efforts between the treatments, which is also in line with the ranking of average efforts in the experiment. However, since loss aversion diminishes incentives in the severetreatment, it cannot explain our major empirical puzzle from the experiment.

Replacing the exogenous reference income $Y^{R}$ by an endogenous one will not alter our finding that loss aversion cannot explain our puzzling result in the severe-treatment. Analogously to Gill and Stone (2010), we can apply the concept of an choice-acclimating personal equilibrium suggested by Köszegi and Rabin (2007) and insert for $Y^{R}$ in (2) the expected tournament income conditional on players' effort choices, $\left(w_{H}+w_{L}\right) p\left(a_{i}\right) p\left(a_{j}\right) / 2$. Thus, player $i$ 's objective function now reads as

$$
\begin{aligned}
& \frac{p\left(a_{i}\right) p\left(a_{j}\right)}{2}\left(w_{H}+g\left(w_{H}-\left(w_{H}+w_{L}\right) \frac{p\left(a_{i}\right) p\left(a_{j}\right)}{2}\right)\right) \\
& +\frac{p\left(a_{i}\right) p\left(a_{j}\right)}{2}\left(w_{L}+l\left(w_{L}-\left(w_{H}+w_{L}\right) \frac{p\left(a_{i}\right) p\left(a_{j}\right)}{2}\right)\right)-c\left(a_{i}\right) .
\end{aligned}
$$

The first-order condition yields ${ }^{9}$

$$
\begin{gathered}
\quad \frac{p\left(a_{j}\right)}{2}\left(w_{H}+g\left(w_{H}-\left(w_{H}+w_{L}\right) \frac{p\left(a_{i}\right) p\left(a_{j}\right)}{2}\right)\right) \\
+\frac{p\left(a_{j}\right)}{2}\left(w_{L}+l\left(w_{L}-\left(w_{H}+w_{L}\right) \frac{p\left(a_{i}\right) p\left(a_{j}\right)}{2}\right)\right) \\
-\left(g\left(w_{H}+w_{L}\right)+l\left(w_{H}+w_{L}\right)\right) \frac{p\left(a_{i}\right) p\left(a_{j}\right)^{2}}{4}=h\left(a_{i}\right) \Leftrightarrow
\end{gathered}
$$

\footnotetext{
${ }^{8}$ The second-order conditions are always satisfied.

${ }^{9}$ The second-order condition is always satisfied under the specification used in the experiment with $p(a)=a$.
} 


$$
\left[(1+g) w_{H}+(1+l) w_{L}\right] \frac{p\left(a_{j}\right)}{2}-(g+l)\left(w_{H}+w_{L}\right) \frac{p\left(a_{i}\right) p\left(a_{j}\right)^{2}}{2}=h\left(a_{i}\right) .
$$

Inserting for the specification used in the experiment (i.e., $p(a)=a, c(a)=\frac{200}{3} a^{3}$, and $w_{L}=0$ ) and the symmetry condition $a_{i}=a_{j}=a$, rearranging leads to ${ }^{10}$

$$
-(g+l) w_{H} a^{2}-400 a+(1+g) w_{H}=0 .
$$

Hence, equilibrium effort $a^{*}$ is given by

$$
a^{*}=\frac{1}{w_{H}} \frac{\sqrt{w_{H}^{2}(1+g)(g+l)+40000}-200}{g+l}
$$

with

$$
\frac{\partial a^{*}}{\partial l}=-\frac{w_{H}^{2}(g+1)(g+l)+80000-400 \sqrt{w_{H}^{2}(g+1)(g+l)+40000}}{2(g+l)^{2} \sqrt{w_{H}^{2}(g+1)(g+l)+40000}}
$$

which is negative since $w_{H}^{2}(g+1)(g+l)+80000>400 \sqrt{w_{H}^{2}(g+1)(g+l)+40000}$. Equilibrium effort in the severe-treatment under loss aversion with endogenous reference income is, therefore, decreasing in the impact of loss aversion.

\section{Part III: Instructions for the experiment (severe-treatment)}

Welcome to this experiment!

You are taking part in an economic decision-making experiment. All decisions are anonymous, none of the other participants learns the identity of someone having made a certain decision.

The payment is also anonymous, none of the participants learns how much the others have earned. Please read these instructions carefully. If you have any questions please look again at the instructions. If you still have any questions please give us a hand signal.

This experiment consists of several rounds. At first, you receive information about the first round. After having finished this round we will provide additional explanations for the next rounds.

Overview first round

In this round of the experiment you make only one decision. You will be interacting with another player whose identity will not be revealed. You will not play with the same player for a second time during this experiment.

Your own decision as well as the decision of the other player will influence your total payment. Please think carefully about your decision.

All payments of the experiment are calculated in a fictive currency called taler. The exchange rate is 1 Euro for 8 talers.

At the beginning of this round a sum of 75 talers is credited to your experimental account. If you receive any other payments in this round they will be added to the initial amount. At the end of the experiment you will receive you total payment. If you achieve any negative payments they will be subtracted from your initial amount and the remaining sum will be paid.

In this round you make a decision which influences the state you will be in at the end of this round. The player you interact with also makes a decision which influences his state. There are two possible states you can find yourself in. Either you are in State A or in State B. The same is true for the other player. If at least one player is in State B this round of the experiment ends and both players receive zero talers. If both players reach State A a random draw decides which player will receive the payment of 100 talers.

\footnotetext{
${ }^{10}$ Since players are homogeneous, a symmetric equilibrium is the most plausible one.
} 
Course of action in the first round

At the beginning of this round you will be randomly assigned to another player you will play with in this round. Then you will choose a number of points between zero and 100 which can be selected in steps of five. This number indicates the probability of reaching State A. If you choose a score of X the probability to reach State A is X per cent. If you choose zero you will reach State B for sure. If you choose 100 you reach State A for sure. The higher the chosen number of points, the higher are the costs for this number. The costs will be subtracted from your payment at the end of this experiment. You find a detailed survey about the costs at the end of this instruction.

The other player also chooses a number between zero and 100 which influences his state.

After both players have made their decisions the software determines the state of both players and the amount of the according payment. For this purpose the states reached by both players will be compared. If at least one player is in State B both players will receive zero talers. If both players reach State A the decision who will receive the payment of 100 talers will be made randomly. The costs from choosing the number of points will be subtracted from the player's experimental account in any case. After this, this round of the experiment is finished and we will hand out new instructions.

All payments will be settled with your initial endowment. Please note that you will be informed about your results and the payment of this round at the end of the whole experiment.

\section{Overview:}

\begin{tabular}{|ll|}
\hline The following scenarios are possible: & Overview about possible payments: \\
$\begin{array}{l}\text { One player is in State A } \\
\text { while the other player is in State B. }\end{array}$ & $\begin{array}{c}\text { Both players: } 0 \text { taler - costs for the chosen number } \\
\end{array}$ \\
& $\begin{array}{l}\text { Random draw which player receives } 100 \text { talers; } \\
\text { the other player receives zero taler. }\end{array}$ \\
& - costs for the chosen number \\
Both players are in State B. & Both players: 0 taler - costs for the chosen number \\
\hline
\end{tabular}

Overview about the costs for scores between 0 and 100

Please note that the costs are given in talers. Choosing a score of zero leads to costs of zero.

\begin{tabular}{|l|l|l|l|l|l|l|l|l|l|l|}
\hline number & 5 & 10 & 15 & 20 & 25 & 30 & 35 & 40 & 45 & 50 \\
\hline costs & 0.01 & 0.07 & 0.22 & 0.53 & 1.04 & 1.80 & 2.86 & 4.27 & 6.08 & 8.33 \\
\hline number & 55 & 60 & 65 & 70 & 75 & 80 & 85 & 90 & 95 & 100 \\
\hline costs & 11.09 & 14.40 & 18.31 & 22.87 & 28.13 & 34.13 & 40.94 & 48.60 & 57.16 & 66.67 \\
\hline
\end{tabular}

\section{Good luck!}




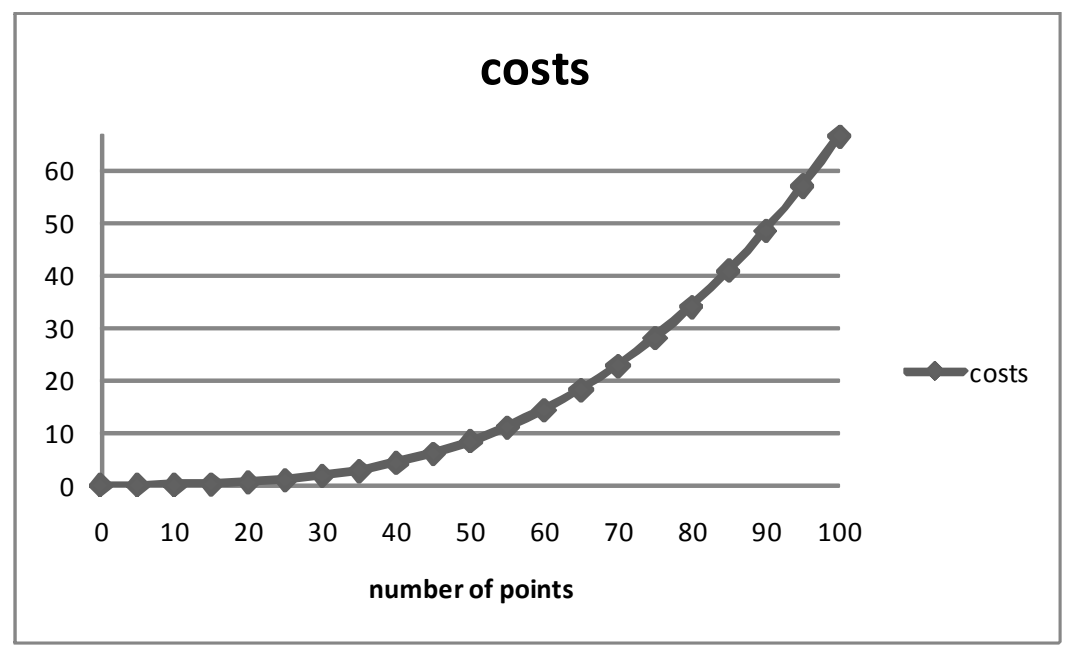

Figure 1: graphical overview

\section{Additional References}

Barberis, N., Huang, M. and Santos, T. (2001): Prospect Theory and Asset Prices. Quarterly Journal of Economics, 116, pp. 1-53.

Chen, K.-P. (2003): Sabotage in Promotion Tournaments. Journal of Law, Economics and Organization, 19, pp. 119-140.

DeMeza, D. and Webb, D. C. (2007): Incentive Design under Loss Aversion. Journal of the European Economic Association, 5, pp. 66-92.

Dixit, A. (1987): Strategic Behavior in Contests. American Economic Review, 77, pp. 891898.

Drago, R., Garvey, G. T. and Turnbull, G. K. (1996): A Collective Tournament. Economics Letters, 50, pp. 223-227.

Gaechter, S., Johnson, E. J. and Herrmann, A. (2010): Individual-Level Loss Aversion in Riskless and Risky Choices. CeDEx Discussion Paper No. 2010-20.

Gill, D. and Stone, R. (2010): Fairness and Desert in Tournaments. Games and Economic Behavior, 69, pp. 346-364.

Gürtler, O. (2011): The First-Order Approach in Rank-Order Tournaments. Economics Letters, 111, pp. 185-187.

Hvide, H. (2002): Tournament Rewards and Risk Taking. Journal of Labor Economics, 20, pp. $877-898$.

Kahneman, D. and Tversky, A. (1979): Prospect Theory: An Analysis of Decisions under Risk. Econometrica, 47, pp. 313-327.

Köszegi, B. and Rabin, M. (2007): Reference-Dependent Risk Attitudes. American Economic Review, 97, pp. 1047-1073.

Schöttner, A. (2008): Fixed-Prize Tournaments versus First-Price Auctions in Innovation Contests. Economic Theory, 35, pp. 57-71. 
Tversky, A. and Kahneman, D. (1991): Loss Aversion in Riskless Choice: A ReferenceDependent Model. Quarterly Journal of Economics, 106, pp. 1039-1061. 